\title{
Long-term neurodevelopmental consequences of intrauterine exposure to lithium and antipsychotics: a systematic review and meta-analysis
}

\author{
Eline M. P. Poels ${ }^{1}$ (D) - Lisanne Schrijver ${ }^{1} \cdot$ Astrid M. Kamperman $^{1} \cdot$ Manon H. J. Hillegers $^{2} \cdot$ Witte J. G. Hoogendijk $^{1}$. \\ Steven A. Kushner ${ }^{1}$. Sabine J. Roza ${ }^{1}$
}

Received: 5 March 2018 / Accepted: 31 May 2018 / Published online: 11 June 2018

(c) The Author(s) 2018

\begin{abstract}
Lithium and antipsychotics are often prescribed to treat bipolar disorder or psychotic disorders in women of childbearing age. Little is known about the consequences of these medications during pregnancy for the developing child. The objective of this article is to systematically review findings from preclinical and clinical studies that have examined the neurodevelopmental consequences of intrauterine exposure to lithium and antipsychotics. A systematic search was performed in Embase, Medline, Web of Science, PsychINFO, Cochrane, and Google Scholar. Clinical and experimental studies were selected if they investigated neurodevelopment of offspring exposed to lithium or antipsychotics during gestation. Quality of clinical and preclinical studies was assessed by the Newcastle-Ottawa Scale and the SYRCLE's risk of Bias tool, respectively. In total, 73 studies were selected for qualitative synthesis and three studies were selected for quantitative synthesis. Of preclinical studies, 93\% found one or more adverse effects of prenatal exposure to antipsychotics or lithium on neurodevelopment or behaviour. Only three clinical cohort studies have investigated the consequences of lithium exposure, all of which reported normal development. In $66 \%$ of clinical studies regarding antipsychotic exposure, a transient delay in neurodevelopment was observed. The relative risk for neuromotor deficits after in utero exposure to antipsychotics was estimated to be 1.63 (95\% CI $\left.1.22-2.19 ; I^{2}=0 \%\right)$. Preclinical studies suggest long-term adverse neurodevelopmental consequences of intrauterine exposure to either lithium or antipsychotics. However, there is a lack of high-quality clinical studies. Interpretation is difficult, since most studies have compared exposed children with their peers from the unaffected population, which did not allow correction for potential influences regarding genetic predisposition or parental psychiatric illness.
\end{abstract}

Keywords Lithium · Antipsychotics · Pregnancy · Neurodevelopment $\cdot$ Intrauterine exposure

Electronic supplementary material The online version of this article (https://doi.org/10.1007/s00787-018-1177-1) contains supplementary material, which is available to authorized users.

Eline M. P. Poels

e.poels@erasmusmc.nl

1 Department of Psychiatry, Erasmus University Medical Center, 's-Gravendijkwal 230, 3015 CE Rotterdam, The Netherlands

2 Department of Child and Adolescent Psychiatry, Erasmus University Medical Center, Rotterdam, The Netherlands 


\section{Key points}

Preclinical studies suggest a harmful effect of lithium on motor activity, developmental milestones and reflexes, spatial memory and brain weight

Only three clinical cohort studies on the development of children with in utero exposure to lithium are published in the literature. They report normal development.

Most preclinical studies found a harmful effect of intrauterine exposure to antipsychotics on motor activity, developmental milestones and reflexes and spatial memory

Clinical studies suggest a delay in motor functioning of children with in utero exposure to antipsychotics. In several studies, this delay appeared to be transient

\section{Introduction}

Patients with bipolar disorder or a psychotic disorder are often treated with lithium and/or antipsychotics in the acute phase of the disease and chronically for relapse prevention $[1,2]$. As a substantial proportion of patients with bipolar disorder or a psychotic disorder are women of childbearing age, knowledge of the potentially deleterious consequences of intrauterine exposure to lithium and/or antipsychotics is critically important for optimally weighing the risks and benefits of different pharmacotherapy options. Continuation of maintenance treatment during pregnancy is often necessary to maintain symptom stability and prevent relapse, while discontinuation of lithium or antipsychotics is associated with a higher relapse risk [3-5].

The teratogenic, obstetric and neurodevelopmental consequences of intrauterine exposure to lithium and/or antipsychotics have remained poorly defined, largely due to the difficulty of implementing feasible study designs that avoid confounding by indication. Multiple studies have reported a positive association between intrauterine exposure to lithium and the risk of cardiovascular anomalies [6-10]. Lithium use during pregnancy has also been associated with an increased rate of miscarriages and preterm delivery [7, 9]. Similarly, antipsychotic use during pregnancy has been associated with higher rates of preterm delivery and low birth weight, as well as neonatal withdrawal symptoms, sedation and extrapyramidal side effects [11, 12]. However, severe mental illness, the indication for which lithium and antipsychotics are overwhelmingly prescribed during pregnancy, is also associated with increased risk of obstetric and neonatal complications independent of medication [13-15]. Therefore, confounding by indication has remained a challenging issue limiting the conclusiveness of previously observed associations between neonatal outcomes and medication exposure during pregnancy.

Further compounding the issue of study design, little is known about the long-term neurodevelopmental consequences of intrauterine exposure to lithium or antipsychotics. It is widely assumed that the fetal environment influences lifetime disease risk based on Barker's hypothesis of 'fetal and infant origins of adult life' $[16,17]$. Following this reasoning, adverse fetal or neonatal consequences of intrauterine exposure to lithium and/or antipsychotics might be expected to have neurodevelopmental consequences that extend well beyond infancy. Regarding the cellular mechanisms of lithium, a neuroprotective effect is suggested through inhibition of glycogen synthase kinase-3 (GSK-3) [18, 19]. Mechanisms of antipsychotic action differ between the different types of antipsychotic medication with dopamine D2 receptor antagonism as the general pharmacodynamic property [20]. Several studies have suggested that atypical antipsychotics, but not typical antipsychotics, may also have neuroprotective effects [21]. Evidence from clinical neuroimaging studies in adults suggests that the use of lithium or antipsychotic medication can influence brain structure. Structural magnetic resonance imaging (MRI) studies have shown that lithium is associated with increases or normalization of gray matter volume in fronto-limbic brain structures [22], while antipsychotic medication has been associated with decreased brain volume and increased ventricular size [23]. Based on this information one might expect similar, or even larger, effects when not the adult but the fetus is exposed during a crucial stage of neurodevelopment.

The objective of this article is to systematically review and synthesize findings drawn from both preclinical and clinical studies examining long-term neurodevelopmental outcomes following intrauterine exposure to lithium or antipsychotics, in an effort to gain further insight into the risks associated with the use of these medications during pregnancy.

\section{Methods}

\section{Search strategy for systematic review}

A systematic search was performed by a trained librarian in the following databases: (1) Embase, (2) MEDLINE, (3) Web of Science, (4) PsychINFO, (5) Cochrane, and (6) Google Scholar, from their respective inceptions through June 8, 2017 to identify studies that investigated the longterm neurodevelopmental consequences of intrauterine exposure to lithium or antipsychotics. The search included the following elements: lithium, antipsychotics, (neuro) development and intrauterine exposure. All elements were transformed into a thesaurus suitable for each specific database. The exact search terms per database are reported in the Supplementary material (Supplement 1). 


\section{Study selection}

Studies were considered eligible for inclusion if they were written in the English language and investigated the longterm neurodevelopment, defined as neurodevelopment beyond the newborn period, of offspring exposed to lithium or antipsychotics during gestation. Experimental preclinical investigations and clinical investigations were considered eligible for inclusion. Case reports were also included in this review. Two reviewers (EP and LS) independently screened the title and abstract of all records identified by our database search. Full text articles were obtained from the studies selected during this first screening step. Both reviewers independently selected the full text articles that met the eligibility criteria. The inclusion of both reviewers was compared and consensus was made on the final inclusion. An additional search was performed on the reference section of relevant studies and review articles to screen for other eligible articles that were otherwise not identified by our structured search.

\section{Data extraction}

Two authors (EP and LS) independently extracted data on study design, sample size and characteristics, medication dosage and exposure period, follow-up time, and behavioural, cognitive and neurological outcome measures. The data were summarized in a data extraction form. Studies were categorized by medication type and study design, and results were reported descriptively in accordance with the PRISMA statement [24].

\section{Assessment of the risk of bias and the quality of studies}

Methodological quality and risk of bias was assessed independently for each study by two reviewers (EP and LS). Risk of bias in preclinical studies was assessed with the SYRCLE's risk of Bias tool [25]. This tool was recently developed to assess risk of bias and has been adjusted for specific aspects of animal intervention studies. The Newcastle-Ottawa Scale (NOS) [26] was used for clinical studies. The NOS assesses the risk of bias of observational studies based on selection, comparability and outcome criteria. The NOS rating scale varies from zero to nine; with zero representing the highest risk of bias and nine the lowest risk.

\section{Procedure for meta-analysis}

For our meta-analysis, we used the same search strategy as mentioned before. Only clinical investigations were included in the meta-analysis with the goal to enhance further insight into the risks associated with the use of these medications during pregnancy in humans. Pooling was performed per type of neuropsychological outcome and per group of medication exposure (lithium or antipsychotics) over a minimum of two studies. Fixed and random-effect estimation was used. In case of substantial heterogeneity, a random-effect estimation provides more reliable pooled results. Results are plotted in a forest plot. Cochran's $Q$ test, and $I^{2}$ statistics were used to quantify heterogeneity across trials. $I^{2}>40 \%$ was considered as substantial heterogeneity. The influence of intrauterine exposure to lithium or antipsychotics on neuropsychological development over time was estimated using random effects meta-regression analysis. Statistical analyses were performed using the 'Metan package' in Stata 15 [27].

\section{Results}

\section{Study selection}

The study selection process is presented in Fig. 1. Our initial search produced a total of 1985 articles. After duplicates were removed, 1427 articles remained. Based on the screening of title and abstract, 182 full text articles were examined for eligibility, of which 118 were excluded (Fig. 1). In total, 73 studies were included in the qualitative synthesis, of which nine studies were included through manual (nonstructured) identification. Additionally, three studies were included in the quantitative synthesis.

\section{Study characteristics}

The characteristics and results of the preclinical investigations included in the qualitative analysis are summarised in Table 1 and 2. The characteristics and results of the clinical studies can be found in Table 3 and 4. Table 1 and 2 in the Supplementary Material (Supplement 2) present the characteristics and results of case reports.

Of the 73 studies included in the qualitative analysis, 29 were preclinical investigations of which seven examined lithium exposure and 22 examined antipsychotics exposure. Most preclinical studies were performed in rats, some in mice and one study on lithium exposure used zebrafish. There is a large variety of the measurements used to assess neurodevelopment in animal models (Table 1,2 ). The exposed period was generally during gestation, although several studies also investigated the effect of exposure during lactation. Postnatal brain development in rodents up to postnatal day 10 is considered analogous to prenatal brain development in humans [28].

In total, we found 13 clinical cohort studies of which three involved lithium exposure and ten involved antipsychotics 


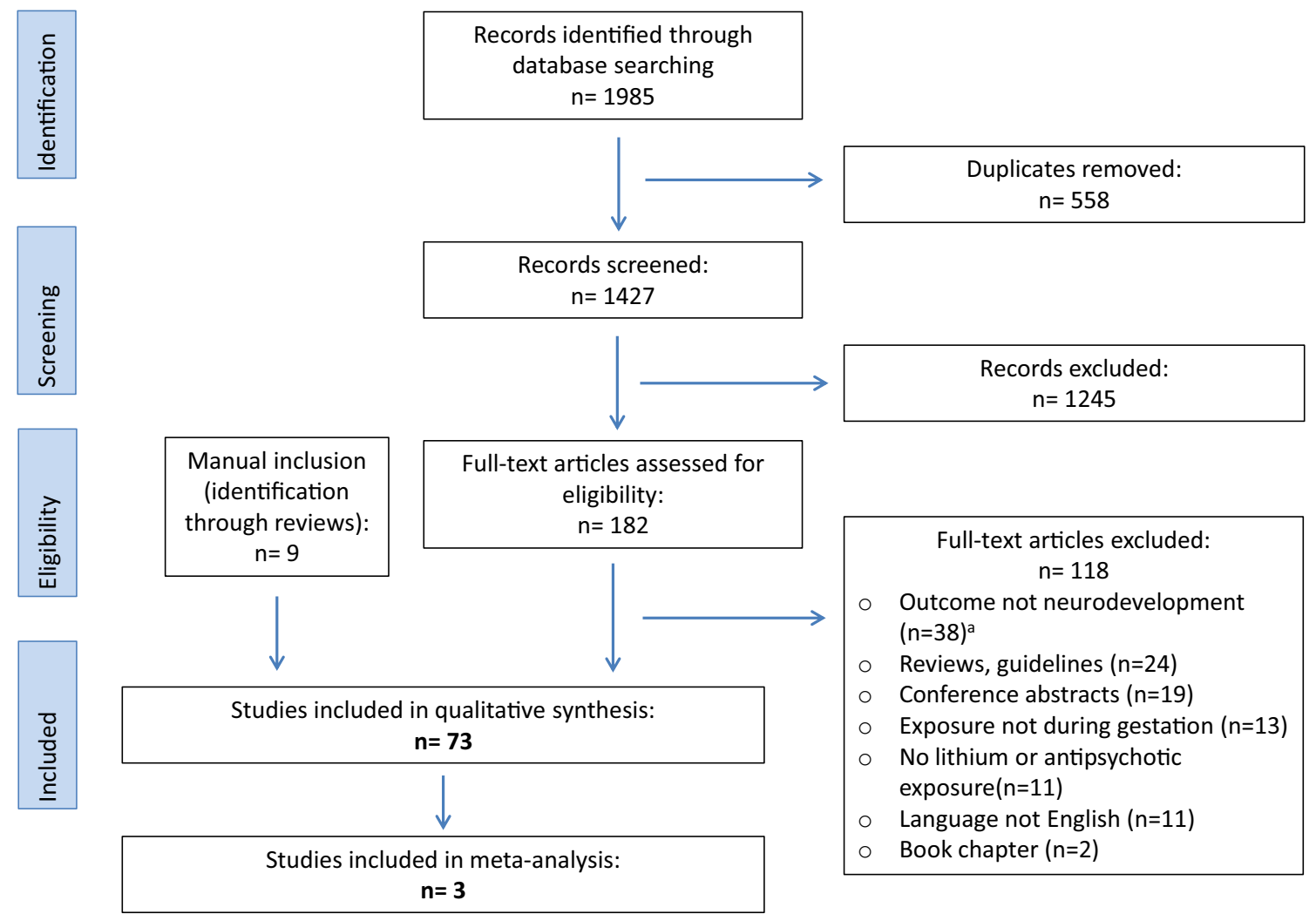

Fig. 1 Flowchart of the study selection process in this systematic review and meta-analysis. ${ }^{\mathrm{a} O u t c o m e}$ of the excluded studies: cell development $(n=4)$, teratogenicity $(n=5)$, neonatal outcome only $(n=14)$,

exposure (Table 3, 4). Study samples varied from 14 to 2141 exposed subjects. Mean follow-up duration ranged from 1 to 15 years in studies involving lithium exposure and from 14 days to 5 years in studies involving antipsychotic exposure. Assessment of neurodevelopment varied between cohort studies. Out of the three clinical studies involving lithium exposure, one used standardized assessments, while the other two relied on an invalidated questionnaire or telephone interview. Most studies involving antipsychotic exposure used standardized objective assessments, but some studies relied solely on invalidated questionnaires or interview. Additionally, 31 case studies were included, of which 5 involved intrauterine lithium exposure and 26 involved intrauterine antipsychotics exposure (Supplement 2).

\section{Lithium}

\section{Preclinical investigations}

Sechzer et al. [29] investigated the long-term developmental consequences of prenatal and early postnatal lithium exposure in rats. Female rats were treated with lithium during pregnancy and lactation. Development of the startle obstetric outcome and teratogenicity $(n=9)$, fetal development $(n=2)$, endocrine and cardiologic follow-up $(n=1)$, weight gain and mortality $(n=1)$, treatment choice $(n=1)$, sexual development $(n=1)$

response and depth perception in the offspring were delayed. At the age of 4 months, pups exhibited lower spontaneous activity during open field activity testing. A similar study investigated the neurodevelopmental effect of lithium exposure from day 1 of pregnancy until postnatal day 15 [30]. Decreased locomotor activity and delayed development of sensory motor reflexes were observed in lithium-exposed mice. Whether these developmental delays were caused by prenatal or early postnatal exposure to lithium could not be determined. Nery et al. [31] studied the behavioural effects of lithium exposure on the development of zebrafish embryos and reported decreased locomotion compared to non-exposed embryos. Additionally, several studies have replicated a delay in eye opening [29, 30, 32] and decreased avoidance behaviour $[32,33]$ in mice and rats exposed to lithium during gestation and/or lactation. One study found impaired performance on the T-maze test [33]. Messiha et al. [34] found lower brain weights in lithium exposed offspring at the age of 37 days. No changes in social, defensive, threatening or aggressive behaviour was observed in lithiumexposed mice [35].

In summary, preclinical studies suggest a deleterious effect of lithium on motor activity, developmental milestones and reflexes, spatial memory and brain weight. 


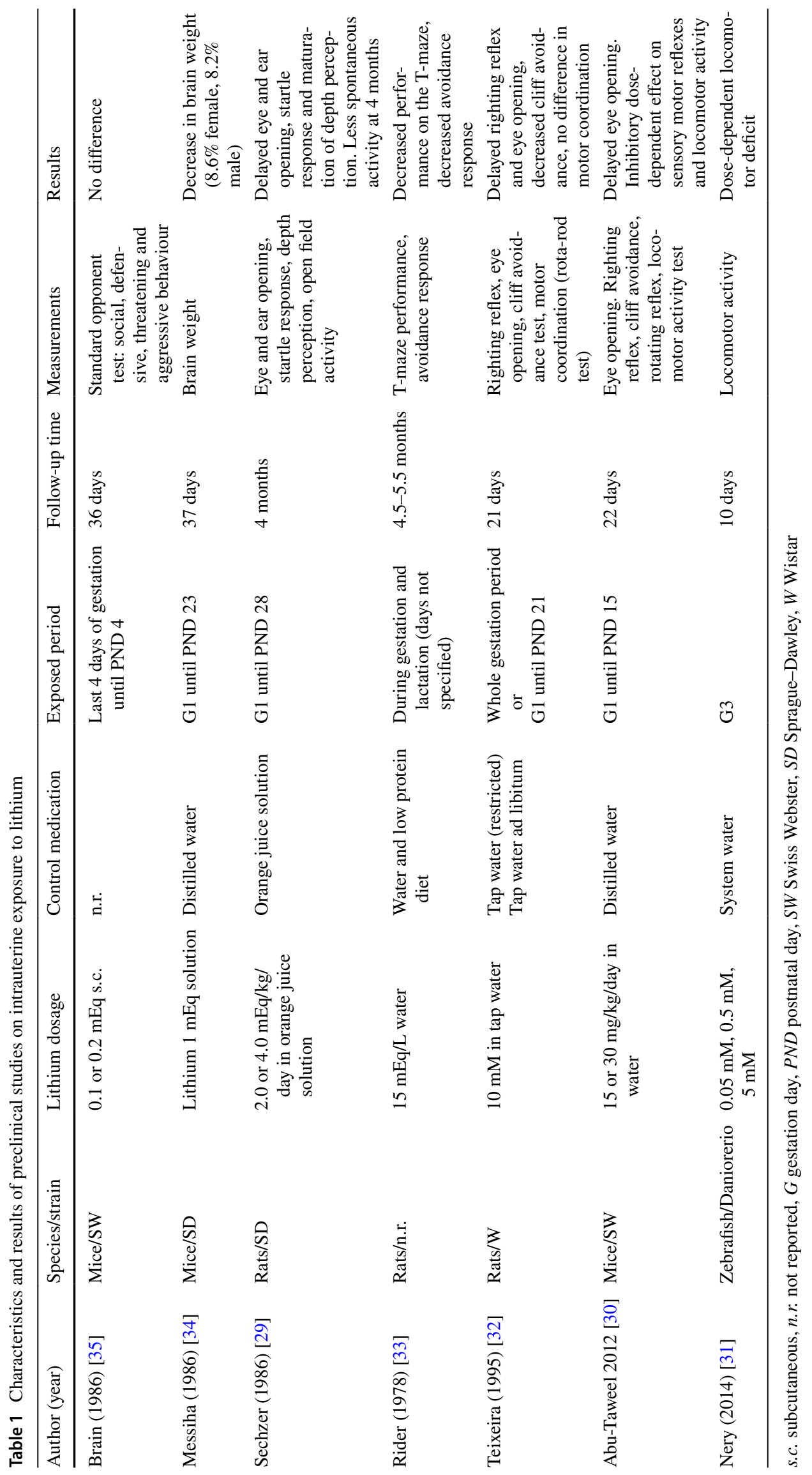




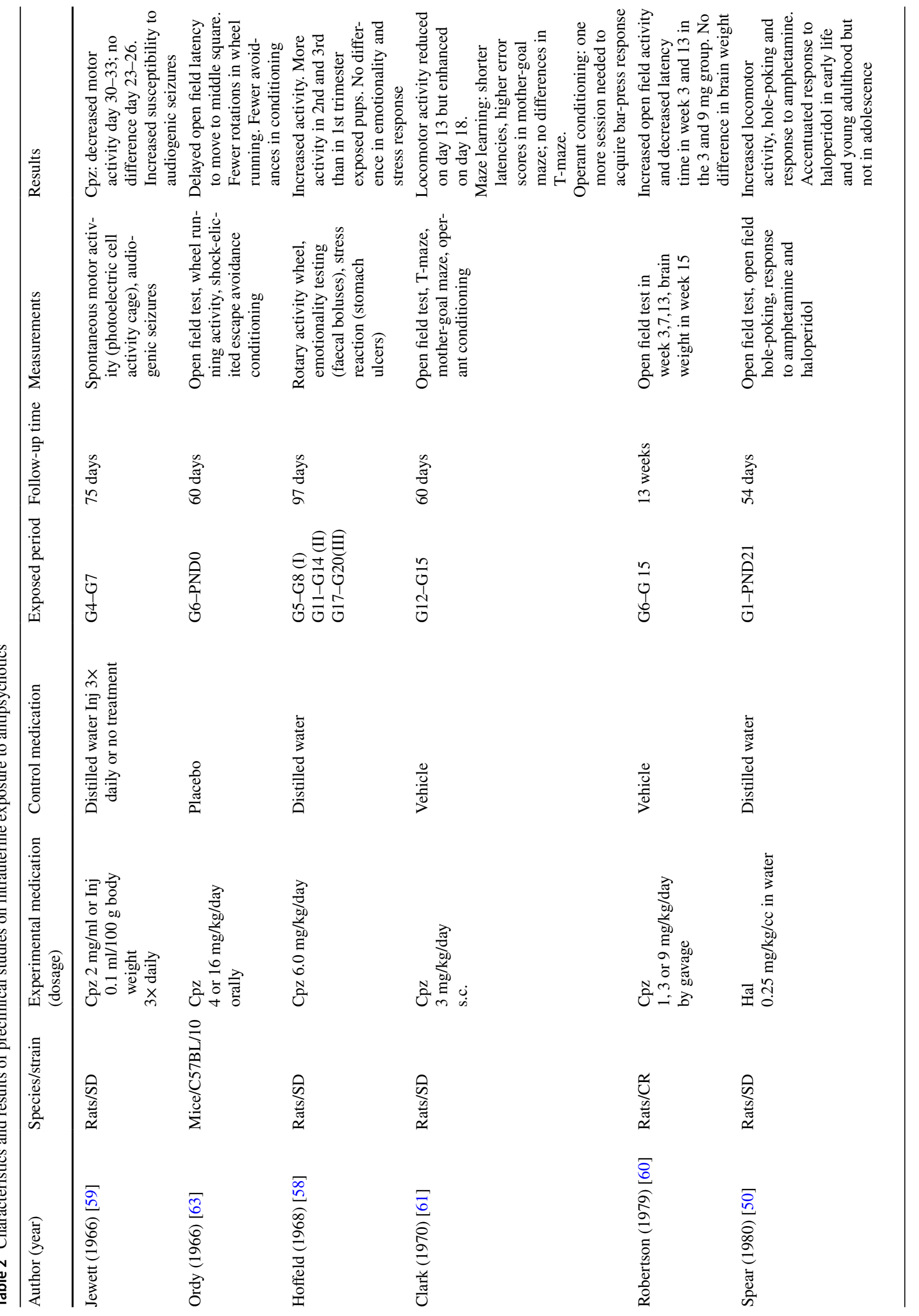




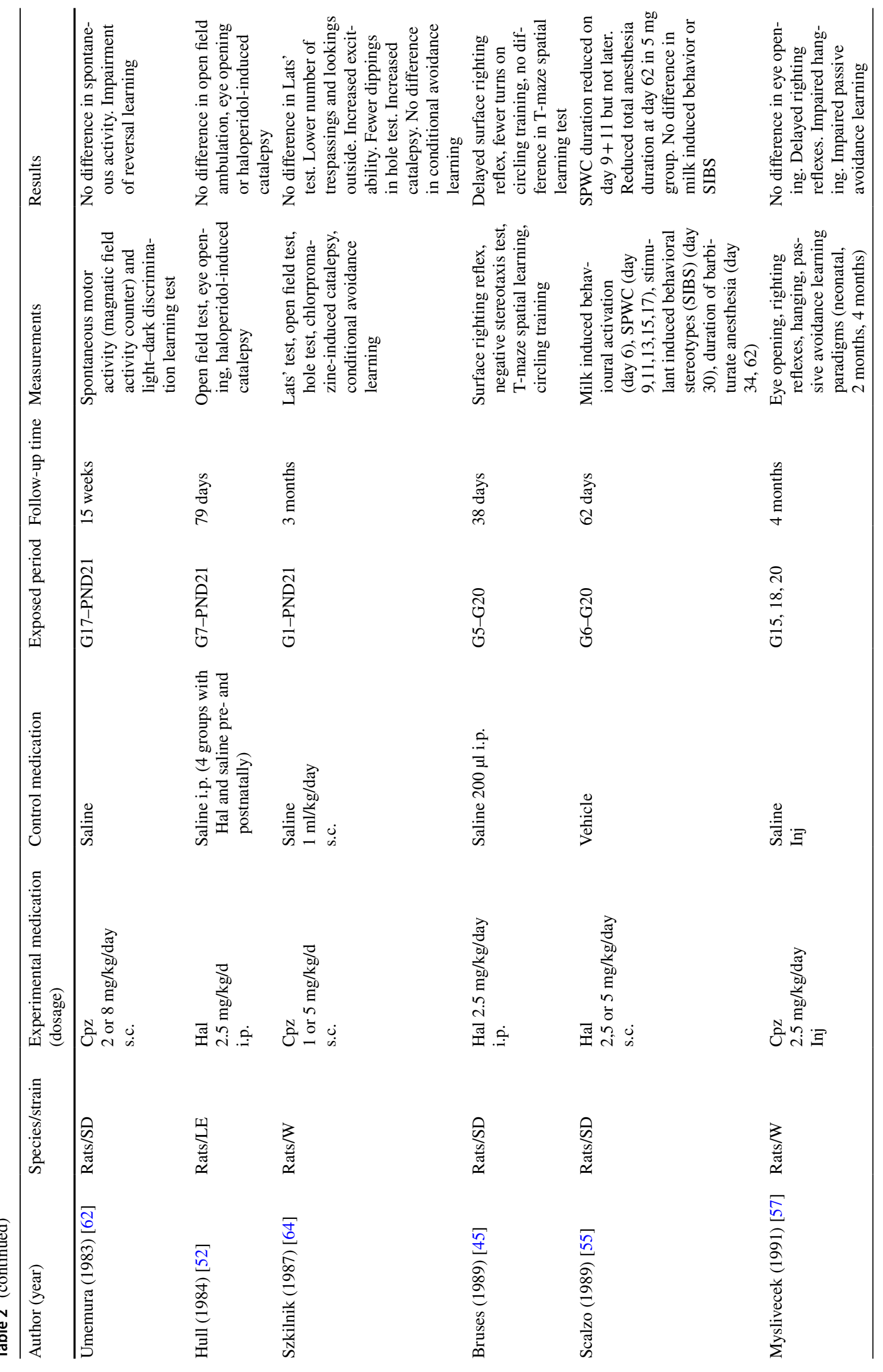




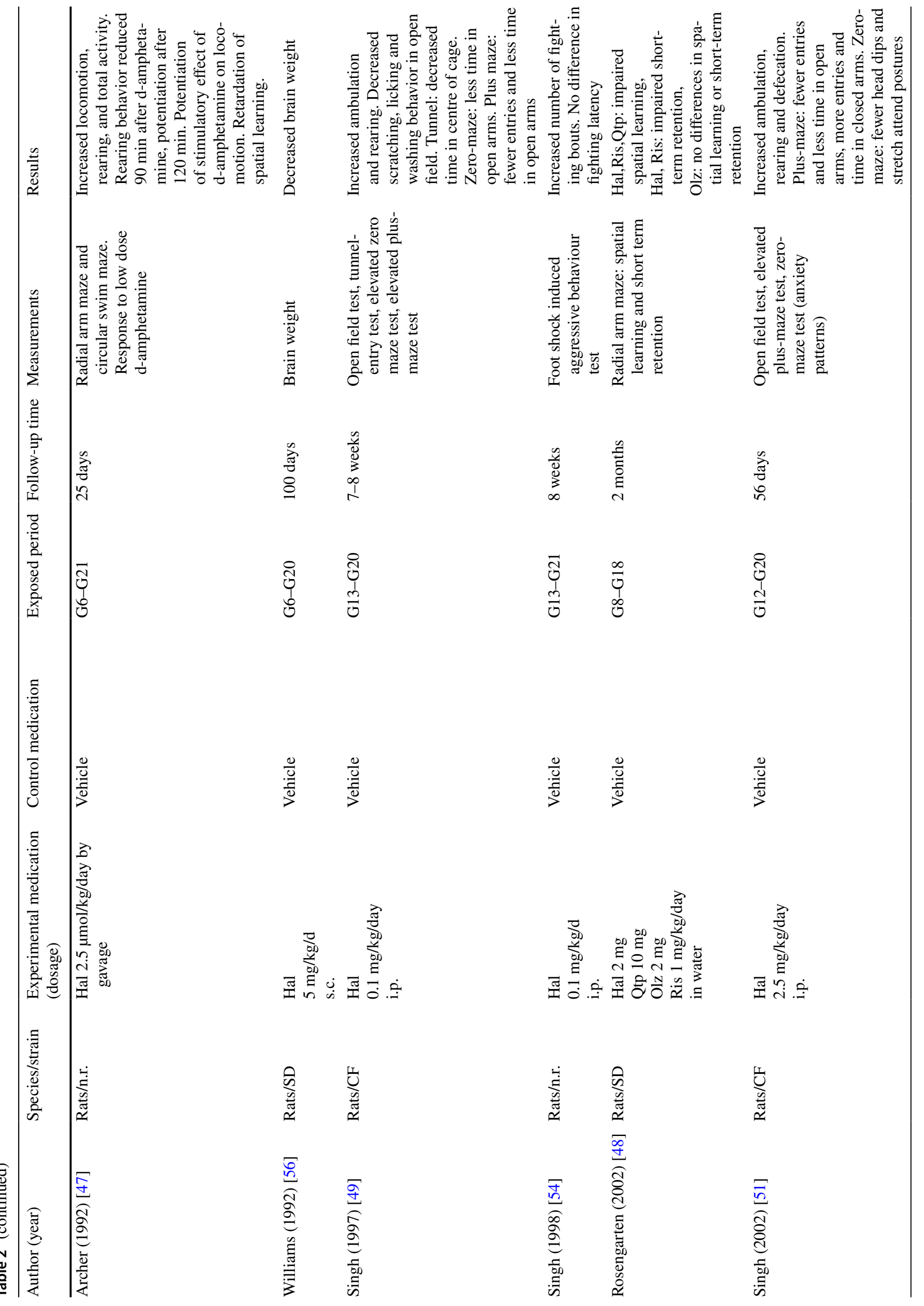




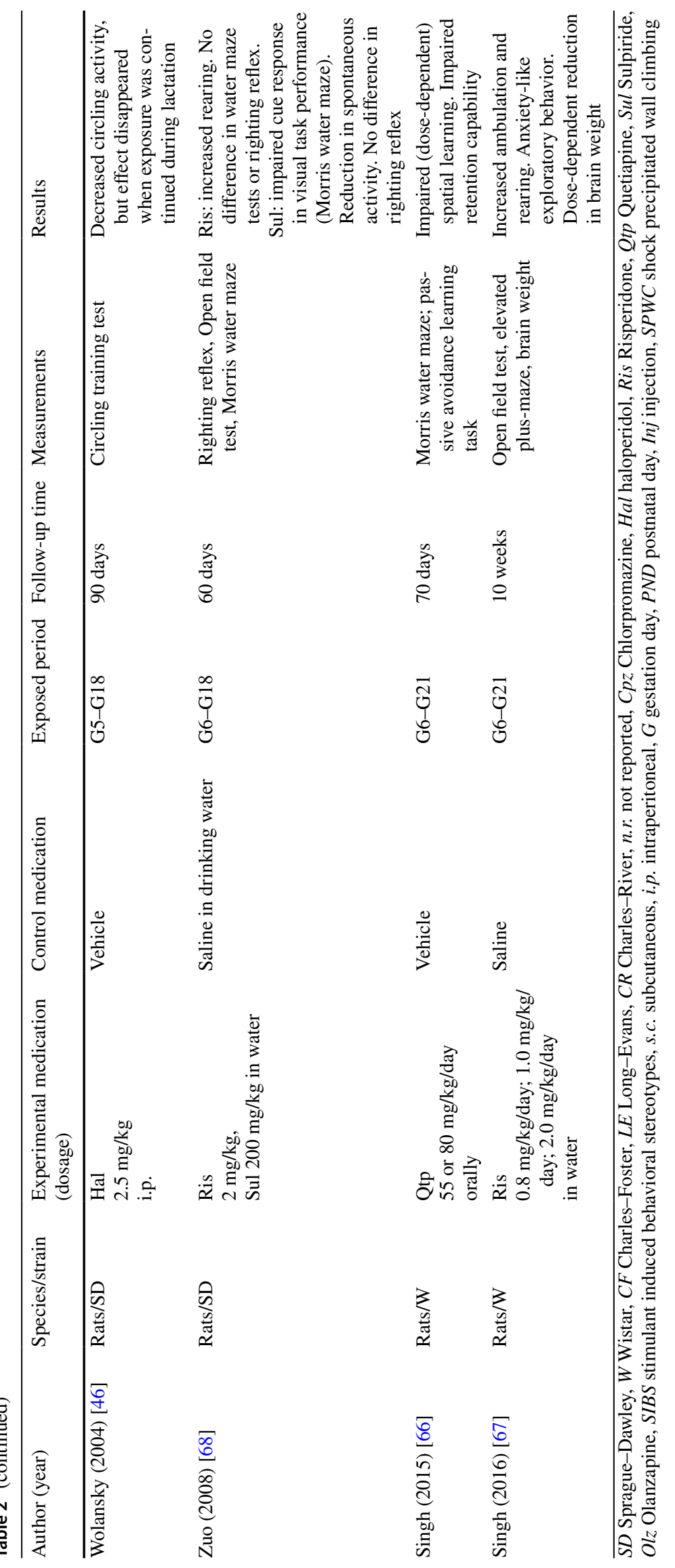


Table 3 Characteristics of clinical studies on neurodevelopmental outcome after intrauterine exposure to lithium

\begin{tabular}{|c|c|c|c|c|c|c|c|c|}
\hline Author (year) & Study design & Sample size & $\begin{array}{l}\text { Lithium daily } \\
\text { dosage }\end{array}$ & $\begin{array}{l}\text { Treatment } \\
\text { indication }\end{array}$ & Follow-up time & Measurements & Results & NOS \\
\hline $\begin{array}{l}\text { Schou (1976) } \\
\text { [36] }\end{array}$ & $\begin{array}{l}\text { Prospective } \\
\text { cohort study }\end{array}$ & $\begin{array}{l}\text { Exposed }=60 \\
\text { Controls }=57\end{array}$ & n.r. & n.r. & Mean: 7 years & $\begin{array}{l}\text { Developmental } \\
\text { questionnaire }^{\mathrm{a}}\end{array}$ & $\begin{array}{l}\text { No difference } \\
\text { in rate of } \\
\text { abnormal } \\
\text { development }\end{array}$ & 7 \\
\hline $\begin{array}{l}\text { Jacobson } \\
\quad(1992) \text { [37] }\end{array}$ & $\begin{array}{l}\text { Prospective } \\
\text { cohort study }\end{array}$ & $\begin{array}{l}\text { Exposed }=22 \\
\text { Controls }=\text { n.r. }\end{array}$ & Mean: $927 \mathrm{mg}$ & $\begin{array}{l}\text { Major affective } \\
\text { disorders }\end{array}$ & $\begin{array}{l}\text { Mean: } \\
61 \text { weeks, } \\
\text { range: } \\
1-9 \text { years }\end{array}$ & $\begin{array}{l}\text { Telephone inter- } \\
\text { view on the } \\
\text { attainment of } \\
\text { developmental } \\
\text { milestones }\end{array}$ & No difference & 3 \\
\hline $\begin{array}{l}\text { vd Lugt (2012) } \\
\text { [38] }\end{array}$ & Cohort study & $\begin{array}{l}\text { Exposed }=15 \\
\text { No controls }\end{array}$ & n.r. & $\begin{array}{l}\text { Bipolar dis- } \\
\text { order }\end{array}$ & $3-15$ years & $\begin{array}{l}\text { Development } \\
\text { questionnaire }^{\mathrm{a}} \\
\text { IQ by BSID or } \\
\text { WPPSI/WISC } \\
\text { Hempel or } \\
\text { Touwen } \\
\text { neurological } \\
\text { examination } \\
\text { Child Behavior } \\
\text { Checklist* }\end{array}$ & $\begin{array}{l}\text { MND }(n=1) \text {. } \\
\text { Low V- } \\
\text { IQ + T-IQ } \\
\text { normal P-IQ } \\
(n=1) \\
\text { Subclinical } \\
\text { anxiety prob- } \\
\text { lems }(n=2) \text {. } \\
\text { Subclinical } \\
\text { oppositional } \\
\text { problems } \\
(n=1)\end{array}$ & 6 \\
\hline
\end{tabular}

n.r. not reported, BSID Bayley Scale of Infant Development, WPPSI Wechsler Preschool and Primary Scale of Intelligence, WISC Wechsler Intelligence Scale for Children, $M N D$ minor neurologic dysfunction; NOS: Newcastle-Ottawa Scale

${ }^{a}$ parent report

\section{Clinical investigations}

Neurodevelopment of 97 children with in utero exposure to lithium has been investigated in clinical cohort studies. Overall, most children were reported to have typical neurodevelopmental trajectories. Schou analysed data from the Scandinavian Register of Lithium Babies to compare neurodevelopmental outcomes in lithium-exposed children $(n=60)$ with their non-exposed siblings $(n=57)$ (average age, 7 years) [36]. Outcomes were assessed by questionnaire and based solely on mothers' subjective retrospective assessment of their children's developmental milestones. No significant differences were observed between the lithiumexposed children and their siblings.

In a prospective multicenter study, major developmental milestones were examined between a sample of 22 lithiumexposed children with non-exposed children [37]. Subjects were screened for study inclusion from among mothers who contacted the public teratogen information services to discuss the potential risks of prescription medication use during pregnancy. Data were collected by telephone interview. No differences were observed between lithium-exposed versus non-exposed children in the age at which they achieved major developmental milestones.

In an observational cohort study, 15 lithium-exposed children between 3 and 15 years old were investigated [38]. Standardized validated tests were used to assess growth, neurological, cognitive and behavioural outcomes. When compared to norms from the general population, most lithium-exposed children scored lower on the Block patterns subtest of the Wechsler Intelligence Scale for Children (WISC-III-NL). In contrast, no differences in growth or behavioural outcomes were observed. One child in this study exhibited subclinical neurological findings. Importantly, however, the conclusiveness of this study was hampered by the lack of a matched non-exposed control group ascertained in parallel with the lithium-exposed group, but rather relied upon an independently collected general population cohort dataset.

In summary, there is a paucity of clinical data on the neurodevelopment of children with in utero exposure to lithium. The three clinical studies published in the literature report normal neurodevelopment.

\section{Case reports}

Neurodevelopmental delay after intrauterine exposure to lithium was reported in four case studies, encompassing a total of eight children [39-42]. Kozma et al. [39] reported on a neonate with neurodevelopmental deficits, including decreased muscle tone, depressed reflexes and diminished social response, during the 2.5 months after birth. However, by 13 months of age, no deficits were observed using 


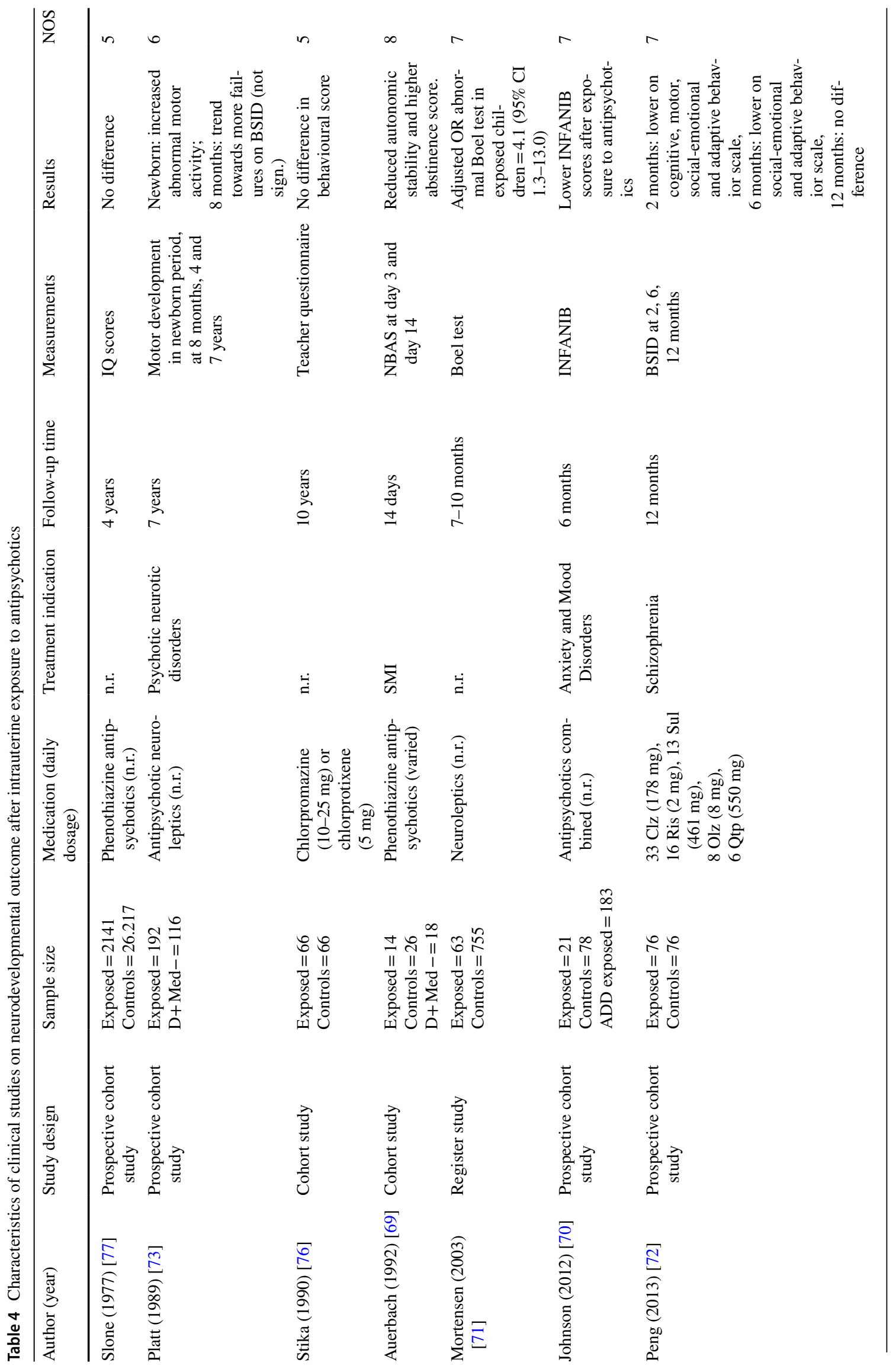




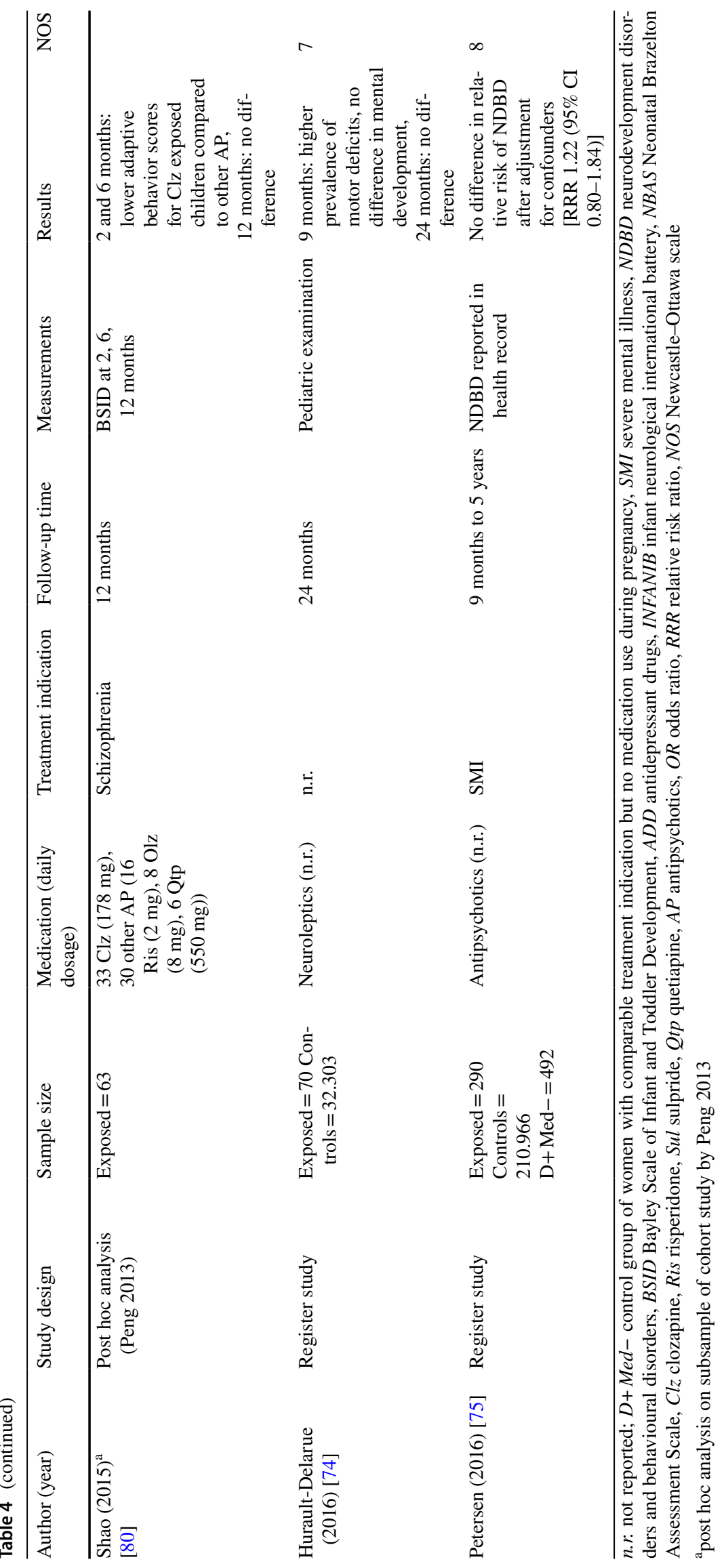


the Bayley Scale of Infant Development. Morrel et al. [43] described a case of lithium toxicity at 35 weeks of gestation (lithium blood level: $2.6 \mathrm{mmol} / \mathrm{L}$ ). The baby was born with primary cardiac muscle dysfunction and treated with isoprenaline at birth. At 12 months of age, cardiac function had normalized but there was evidence of delayed motor development and a concomitant strabismus. Delayed gross motor function was also reported in two cases with prenatal lithium exposure that did not involve lithium intoxication $[41,42]$. One case report reported normal psychomotor development [44].

\section{Antipsychotics}

\section{Preclinical investigations}

Eleven studies have investigated the long-term neurodevelopmental consequences of prenatal haloperidol exposure in rats. Emergence of the surface righting reflex was found to be delayed [45]. Two studies found deficits in a circling training test $[45,46]$, a measure of motor performance and associative learning. Impairments in spatial learning were also found [45, 47, 48] using the Morris water maze, T-maze and radial arm maze. Moreover, the open field test revealed increased rearing, ambulation and general activity [47, 49-51]. One study reported finding no difference in ambulation on the open field test [52]. Notably, since behaviour in the open field test is influenced not only by locomotor activity, but also by anxiety and exploratory behaviour [53], additional studies have been performed to further differentiate these phenotypes. Indeed, consistent with an increase in anxiety, rats made fewer entries and spent less time in open arms during elevated zero and plus-maze tests [49, 51]. Moreover, aggressive behaviour was also increased [54]. Duration of shock-precipitated wall climbing was reduced on postnatal days 9 and 11 , and there were no differences in stimulant induced behavioural stereotypes [55]. Lastly, from a neuroanatomical perspective, rats with intrauterine exposure to haloperidol exhibited significantly lower brain weight in adulthood [56].

Eight studies have investigated the long-term neurodevelopmental effects of intrauterine exposure to chlorpromazine in rats. One study systematically investigated the onset of neurodevelopmental milestones [57]. They found no difference in onset of eye opening, but emergence of the righting reflex was delayed. Studies investigating motor development found both increases [58] and decreases [59] in wheel running activity and impairments in a hanging task [57]. In the open field test, latency time was decreased $[59,60]$ and locomotor activity was increased [60, 61]. Similarly, spontaneous activity was normal in one study [62], but decreased in another [63]. Spatial memory was found to be impaired in a mother-goal maze task, whereas no differences were found in a T-maze task [61]. Studies focusing on other types of learning have reported impaired avoidance conditioning [57, 59], reversal learning [62] and operant conditioning [61]. Avoidance conditioning was observed to be normal [64]. A study investigating exploratory behaviour found that rats made fewer hole dippings [64]. Hoffeld et al. [58] did not find changes in emotionality testing. Susceptibility to audiogenic seizures was increased [63]. Brain weights did not differ between chlorpromazine and placebo exposed groups [60].

Several other antipsychotics were examined for neurodevelopmental effects. Rosengarten et al. [65] investigated the possible sequelae of intrauterine exposure to quetiapine, risperidone or olanzapine and found impaired spatial learning in a radial arm maze task for both risperidone and quetiapine, and disrupted short-term retention for quetiapine. Intrauterine exposure to olanzapine did not affect learning or retention. A recently published study also found impaired spatial learning and retention capability in rats with prenatal exposure to quetiapine [66]. Two studies investigated the effects of risperidone exposure during gestation. Singh et al. [67] reported increased ambulation and rearing in the open field test, and increased anxiety-like exploratory behavior in the elevated plus maze test. Intrauterine exposure to risperidone led to a dose-dependent reduction of adult brain weight. Zuo et al. [68] also found increased ambulation, while righting reflexes and spatial memory were normal. In the same study, rats with prenatal exposure to sulpiride exhibited an impaired cue response in a visual task performance and reduced spontaneous activity, while righting reflexes and spatial memory were normal.

In summary, most preclinical studies found a deleterious effect of antipsychotics on motor activity, developmental milestones and reflexes and spatial memory. Additionally, exposure to either haloperidol or risperidone led to decreased brain weight.

\section{Clinical investigations}

In total, neurodevelopmental data of 2934 children with in utero exposure to antipsychotics have been published involving nine clinical cohort studies. Six studies reported neurodevelopmental delays or deficits after prenatal exposure to antipsychotics [69-74], while three studies reported normal developmental outcomes [75-77]. Most studies reported antipsychotic exposure on the basis of a single broad category, which combined a wide variety of antipsychotics. The initial report of abnormalities of motor development in children with intrauterine exposure to antipsychotic was authored by Platt in a cohort of 192 children exposed to antipsychotic neuroleptics and 116 children of women with a history of psychiatric disorders described as psychotic/ 
neurotic but without antipsychotic treatment. Notably, deficits at the neonatal assessment of motor activity were more severe than at 8 months of age, when there was a non-significant trend towards more failures based on the Bayley gross motor assessment [73]. Another study examined 21 children with prenatal antipsychotic exposure, 183 children with prenatal antidepressant exposure and 78 non-exposed children at 6 months of age [78]. Children with prenatal exposure to antipsychotics had lower scores on the infant neurological international battery (INFANIB) compared to children with prenatal antidepressant exposure or non-exposed children. Comparable results were found in a recent register-based study in France [74]. Psychomotor development, assessed by pediatric examination, was compared between 70 children with prenatal neuroleptic exposure and 32.303 nonexposed controls. A higher prevalence of motor deficits was reported in exposed children at 9 months of age, a difference that was no longer present at 24 months of age. No differences in cognitive development were observed. A Danish general population register-based study reported an association between drug prescriptions during pregnancy and results on the Boel test, a psychomotor development test assessed at 7-10 months of age [71]. Specifically, the odds ratio for an abnormal Boel test was 4.1 (95\% CI 1.3-13.0) among children with intrauterine exposure to neuroleptic medication after adjustment for several confounders including gestational age, birth weight and breastfeeding. In contrast, Stika et al. [76] reported finding no discernible adverse behavioural outcomes based on evaluations made by their classroom teachers in 10-year-old children with prenatal neuroleptic exposure.

Using data from two large electronic primary care databases in the UK, Petersen et al. investigated the risks and benefits of psychotropic medication during pregnancy. They compared the prevalence of neurodevelopmental and behavioural disorders in children with prenatal exposure to antipsychotics, children with no antipsychotic exposure whose mothers discontinued antipsychotic treatment before pregnancy and non-exposed children whose mother was not prescribed antipsychotic treatment in the 24 months before pregnancy. They found an increased risk of neurodevelopmental and behavioural disorders in children exposed to antipsychotics with a relative risk ratio (RRR) of 1.58 (95\% CI 1.04-2.40). However, after adjustment for possible confounders, these differences were no longer statistically significant (RRR 1.22, 95\% CI 0.80-1.84) [75]. An earlier study, focused specifically on phenothiazine antipsychotics, similarly reported no difference in intelligence quotient scores among 4-year-old children, of which 2141 had prenatal exposure and 26,217 were non-exposed [77]. Notably, however, a higher burden of neonatal withdrawal symptoms and autonomic instability was reported 14 days after birth in neonates with intrauterine exposure to phenothiazine antipsychotics [69].

More recent studies have also focused on the long-term developmental consequences of intrauterine exposure to atypical antipsychotics. Peng et al. [79] prospectively investigated 76 children with intrauterine exposure to atypical antipsychotics and 76 non-exposed controls, from birth until 12 months of age. Neurobehavioural development was assessed by the Bayley Scale of Infant and Toddler Development (BSID) at 2, 6 and 12 months of age. At 2 months of age, antipsychotic-exposed children exhibited significantly lower scores regarding cognitive, motor, social-emotional, and adaptive behavioural functioning. At 6 months of age, scores regarding social-emotional and adaptive behavioural functioning were still lower, but not significantly different between groups in cognitive or motor scores. In contrast, by 12 months of age none of these effects persisted. A post hoc analysis revealed that children prenatally exposed to clozapine had lower scores on the BSID adaptive behavior scale at the ages of 2 and 6 months compared to children exposed to other atypical antipsychotics [80]. However, this difference was also no longer present at 12 months of age.

Although studies varied in measurements and followup time, five cohort studies [70-74, 80] investigated motor development of children with in utero exposure to antipsychotics. These studies consistently showed a deficit in motor functioning in the first 9 months of life, but which appeared to spontaneously resolve based on subsequent follow-up assessments.

\section{Case reports}

Overall, case studies on intrauterine exposure to first generation antipsychotics have largely reported normal neurodevelopment [81-88]. Additionally, although most case studies involving prenatal exposure to second generation antipsychotics have also reported normal infant and child development [81, 88-101], several case reports have found neurodevelopmental delays or deficits. Two cases reported speech delay, one involving risperidone and the other clozapine [102, 103]. One case reported abnormal behavioral development following prenatal exposure to risperidone and ziprasidone [103]. Impaired motor development has been reported following exposure to olanzapine, clozapine or risperidone [104-106].

\section{Risk of bias and quality of the included studies}

The risk of bias for the included preclinical studies is presented in the Supplementary Material (Supplement 3). Notably, many lack descriptions of the assessed domains, thereby making the risk of bias unclear (e.g., selection bias, performance bias, detection bias or attrition bias). In $34 \%$ of the 
preclinical studies, cross-fostering after birth was applied in order to control for medication-induced changes in maternal care.

NOS scores of clinical cohort studies varied between three and eight points (Table 3 and 4). Only three cohort studies properly controlled for maternal mental illness, widely considered the most important confounder in studies of intrauterine exposure to prescription psychotropic medication. In the other studies, neurodevelopment was compared between children with prenatal exposure to lithium or antipsychotics versus unaffected children, thereby leaving unaddressed the risk of confounding by indication. Moreover, few clinical studies controlled for additional confounders such as maternal age, congenital malformations, preterm birth, or smoking and alcohol use during pregnancy, often because information on these factors was not available. In most studies of antipsychotic exposure, developmental assessments were standardized and validated, although some studies based their results on non-validated questionnaires or information obtained exclusively from medical records. The quality of the included studies on lithium exposure is poor, as only one cohort study used validated measurements of neurodevelopment. Unfortunately, this study did not compare their findings with a formal control group. Regarding case studies, their quality is generally considered low with a high risk of publication bias. Indeed, most case studies did not assess neurodevelopment using validated objective measures.

\section{Meta-analysis}

Three out of five studies that investigated neuromotor deficits in children with in utero exposure to antipsychotics provided sufficient data and were included in a meta-analysis $[70,72,74]$. Figure 2 shows the relative risk of neuromotor deficits for antipsychotic exposure for all reported follow-up assessments (six effect sizes). Pooled relative risk calculated using fixed effect estimation was 1.97 (95\% CI 1.47-2.62; Z value: $4.59, p<0.001)$ with absence of heterogeneity $\left(I^{2} 0 \%\right.$, $p=0.622$ ). Since studies reported multiple follow-up outcomes, this pooled estimate should be interpreted with care.

Two studies [70,72] reported follow-up outcomes at 6 months. The pooled relative risk was 1.63 (95\% CI $1.22-2.19 ; Z$ value $=3.29 ; p=0.001$, fixed effect $)$ with absence of heterogeneity $\left(I^{2}=0 \%, p=0.849\right)$, indicating a $63 \%$ increased risk for neuromotor deficits at 6 months (Fig. 3).

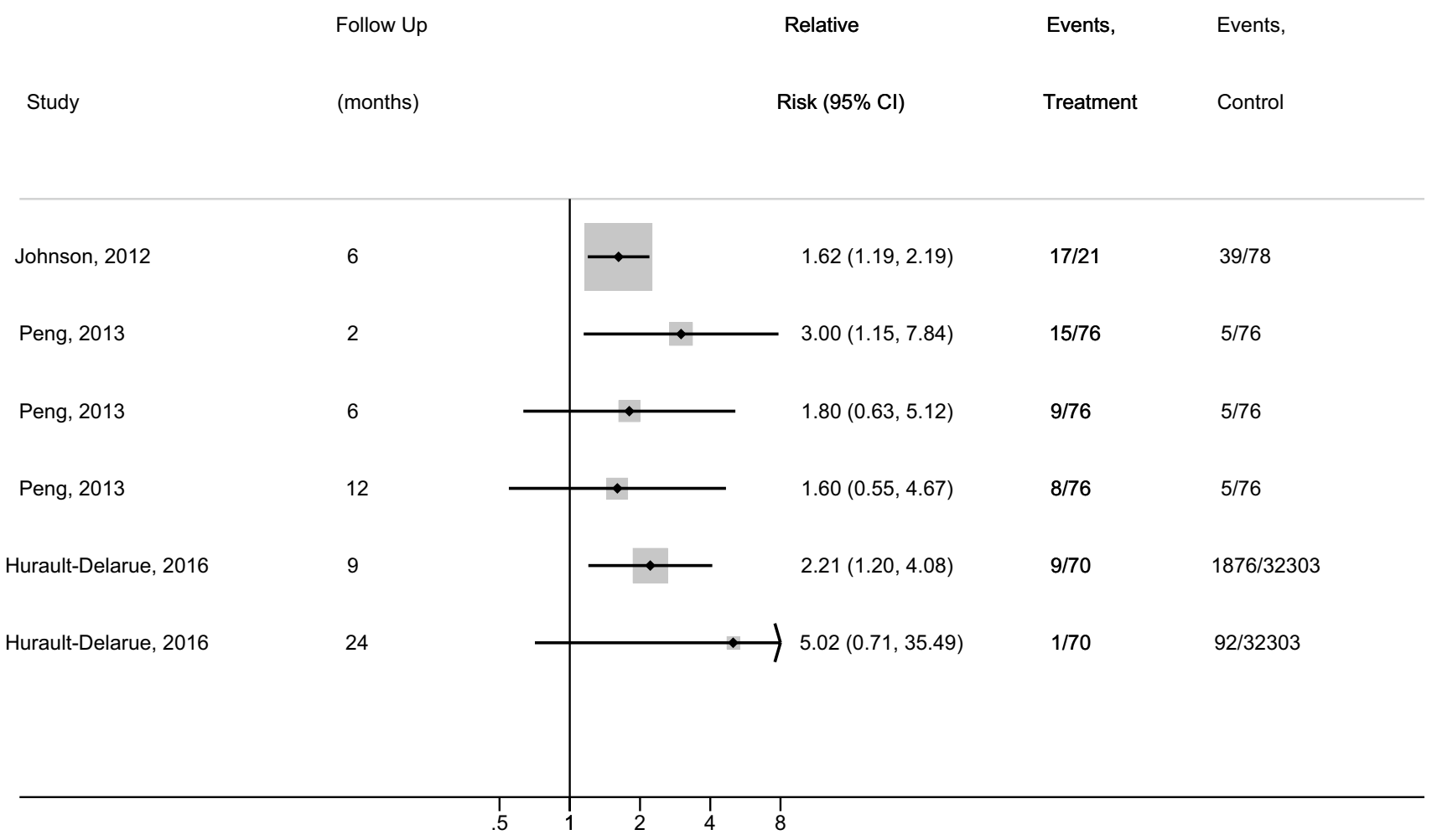

Risk associated with antipsychotic exposure

Fig. 2 Relative risk estimates including the 95\% confidence interval limits of neuromotor deficits for antipsychotic exposure for all reported follow-up assessments 


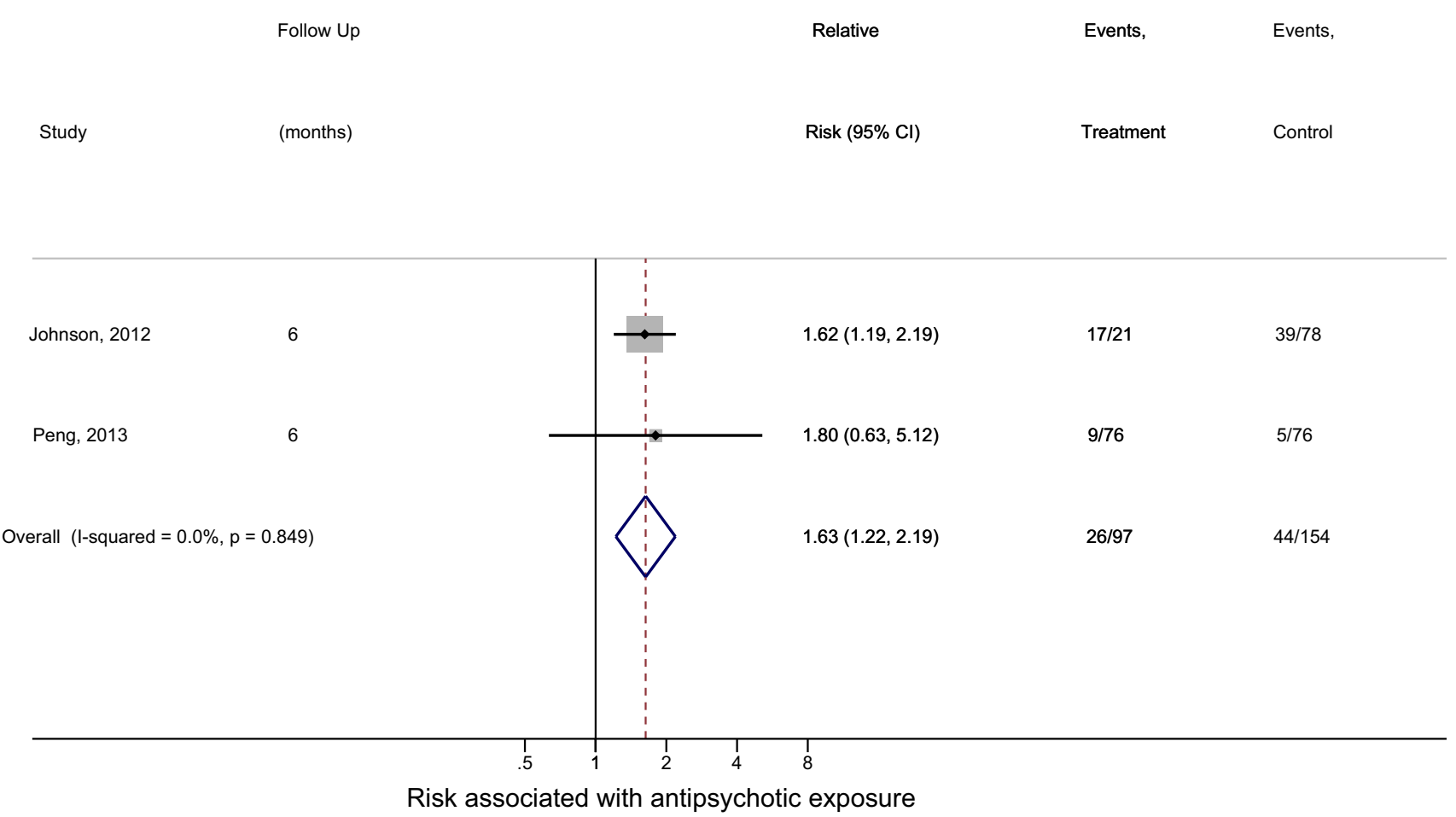

Fig. 3 Relative risk estimates including the 95\% confidence interval of neuromotor deficits for antipsychotic exposure at 6 months of follow-up. The pooled relative risk was estimated using a fixed-effects estimation

Next we performed a random effects meta-regression analysis to study the longitudinal influence of intrauterine exposure to antipsychotics on motor development. For each study, we included the initial follow-up assessment. The direction of the regression coefficient suggested a decrease of the impact of intrauterine exposure to antipsychotics on neuromotor deficits over time. However, there was no statistically significant effect $(-0.03 ; 95 \% \mathrm{CI}-1.26$ to 1.20 ; $p=0.80)$. Residual heterogeneity was substantial $\left(I^{2}=49 \%\right)$. In conclusion, in this meta-analysis we were able to partially confirm the negative effect of antipsychotic exposure on motor development. However, we were not able to confirm the transient nature of the neuromotor deficits.

\section{Discussion}

In this systematic review article and meta-analysis, we present an overview of the current literature regarding longterm neurodevelopmental effects of lithium and antipsychotics. Towards this goal, we included both preclinical and clinical studies. Preclinical studies have the potential to investigate the effect of medication exposure using more optimal study designs in which important biases in clinical studies, such as confounding by indication, can be directly addressed. Notably, although preclinical findings may not always be translatable into clinical practice, they have the potential to provide mechanistic insights and reveal indications of possible risks in situations for which well-controlled high-quality clinical studies are lacking. Undoubtedly, however, disproportionate weight should be given to evidence discerned from relevant clinical studies when helping women to consider the risks and benefits of their perinatal treatment options.

Overall, findings from preclinical studies suggest a deleterious effect of lithium on locomotor activity and delayed development of eye opening and righting reflexes. Additionally, brain weight was found to be lower in lithium-exposed offspring. Clinical studies of offspring neurodevelopment after intrauterine exposure to lithium generally reported normal development. However, two out of the three studies based their results exclusively on retrospective maternal reports, while the third study lacked a formal control group. The lack of clinical studies on the risks of lithium use during pregnancy might be due to the fact that lithium is a naturally occurring element that was never patented. Another explanation for the knowledge gap on long-term neurodevelopmental effects of lithium exposure might be the (earlier recognized) association with cardiac malformations. This association was first reported in the 1970's by Schou et al. and a recent study by Patorno et al. confirmed this association although the authors report that the risk was lower than previously suggested $[10,107]$. These findings have influenced treatment guidelines in the United Stated 
and the United Kingdom, where lithium use during pregnancy is discouraged [108, 109], and possibly also influenced research to focus on congenital malformations rather than on neurodevelopment.

Despite the many differences in methodology, preclinical studies consistently reported adverse neurodevelopmental and behavioural effects of prenatal exposure to antipsychotics. Antipsychotics seem to increase locomotor activity and anxiety, as well as impair cognition, in exposed offspring. Lastly, and of important consideration for clinical translational potential, brain weight was found to be lower in offspring with intrauterine exposure to haloperidol and risperidone. Most studies of antipsychotics involved haloperidol and chlorpromazine, while a much smaller number focused on varied atypical antipsychotics. At present, there is insufficient evidence to conclude whether the neurodevelopmental impact of prenatal exposure to antipsychotics is dependent upon the specific type or class. Findings from clinical studies of antipsychotic exposure are inconsistent and difficult to interpret due to the considerable differences in methodology and follow-up period. Several studies reported a delay in neurodevelopment among infants with intrauterine exposure to antipsychotics. However, these early neurodevelopmental delays were frequently transient, having resolved on subsequent longitudinal follow-up assessments. The most consistent finding was a transient delay in motor development. This was confirmed in our meta-analysis with a relative risk of 1.36 for neuromotor deficits after in utero exposure to antipsychotics at 6 months of follow-up. However, this estimate was based on only two studies. More studies are needed to provide a more robust estimate and to study the course of motor development over time. Most studies had a follow-up period of less than 2 years, for which later-onset neurodevelopmental sequelae cannot be excluded. Based on the currently available reports, no distinction between the various types of antipsychotics can be made as most studies combined different types and classes of antipsychotics into a single broad category, presumably to increase statistical power.

Clinical findings might have been affected by confounding by indication, since most studies compared exposed children to non-exposed children of mothers with no history of psychiatric illness. Therefore, studies have not been able to adequately adjust for genetic predisposition, psychiatric illness during pregnancy, or parenting, all of which would be expected to independently influence child development [110-112]. Regardless of medication exposure, offspring of patients with schizophrenia and bipolar disorder have an increased risk to develop any mental illness [113] and experience more cognitive impairments [114-116]. A recent study found impairment of motor function among children with a familial risk of schizophrenia [117]. Additionally, studies using structural MRI have reported decreased white and gray matter volume in offspring of parents with bipolar disorder or schizophrenia [118-121]. It is therefore of particular importance for future studies to compare psychotropic medication-exposed children to non-exposed children of mothers with similar psychopathology.

Our findings may have been influenced by publication bias, since studies without significant results are less likely to be published [122]. This is particularly the case for preclinical studies. As a result, the rate and severity of neurodevelopmental deficits presented in this review might be an overestimation. However, the paucity of evidence regarding the long-term effects of intrauterine exposure to lithium or antipsychotics may also lead to a blunted motivation to invest in studies of the potential adverse neurodevelopmental consequences and consequent underreporting of associations. Undoubtedly more studies of higher quality will be required in order to address these questions with greater certainty.

Our results show a discrepancy between findings from preclinical and clinical studies, with preclinical studies reporting more discernible neurodevelopmental deficits. As mentioned above, publication bias might be part of the explanation. In addition, many preclinical studies used high dosages of medications, exceeding $80 \%$ occupancy of the D2-receptor causing more side-effects [123]. Lastly, species differences cannot be disregarded as a potential source of discrepancy between pharmacological studies in animals and humans.

High quality clinical studies will be required in order to properly assess the risk of adverse neurodevelopmental effects of intrauterine exposure to lithium and antipsychotics. Randomized controlled trials are often considered the best approach to studying causal inference. However, there is broad consensus that randomized assignment for the purpose of studying medication side effects is unethical [124]. Furthermore, placebo-controlled randomization of women with mental health indications for lithium or antipsychotics is also considered unethical when treatment is medically indicated, but also regarding exposure of the fetus when treatment is not medically indicated. Future studies of neurodevelopmental outcome in children with intrauterine exposure to psychotropic medication will therefore have to continue to rely upon clinical cohort studies, for which non-randomized designs can be well suited for studying unintended pharmacological effects [125]. However, cohort studies should ideally have a prospective design with extended follow-up periods utilizing validated standardized neurodevelopmental outcome measures. Moreover, in an effort to reduce confounding by indication, the primary comparison group for exposed children should involve non-exposed children of mothers with similar psychopathology. Since it is unlikely that medicated and non-medicated pregnant women have the same disease severity, cohort studies should also consider designs in which pregnant women treated with lithium 
or antipsychotics are compared to pregnant women with the same psychiatric disorder but other pharmacological treatments.

The decision for pharmacological treatment during pregnancy should always be decided through a patient-centered discussion with their healthcare provider by carefully weighing the risks and benefits of various treatment options and by developing an individualised treatment plan.

\section{Conclusion}

Prenatal exposure to lithium or antipsychotics has an adverse effect on neurodevelopment and behaviour in mice and rats, but the precise mechanisms remain unclear. In humans, the existence and nature of any effects remains poorly determined. At present, there is insufficient evidence to estimate the neurodevelopmental effects of intrauterine exposure to lithium. Although several studies have reported a transient neurodevelopmental delay following intrauterine exposure to antipsychotics, the current lack of high quality clinical investigations substantially limits the conclusiveness of the available evidence. In particular, improved clinical studies will require prospective designs with longer follow-up periods and more extensive assessments including validated measures of child development, in order to offer more substantiated evidence-based advice to women with bipolar disorder or psychotic disorders regarding the risks and benefits of pharmacotherapy during pregnancy.

Acknowledgements The authors would like to thank Wichor Bramer (Information Specialist, Erasmus Medical Center) for his assistance with the literature search for this study.

\section{Compliance with ethical standards}

Conflict of interest On behalf of all authors, the corresponding author states that there is no conflict of interest.

Open Access This article is distributed under the terms of the Creative Commons Attribution 4.0 International License (http://creativeco mmons.org/licenses/by/4.0/), which permits unrestricted use, distribution, and reproduction in any medium, provided you give appropriate credit to the original author(s) and the source, provide a link to the Creative Commons license, and indicate if changes were made.

\section{References}

1. Geddes JR, Miklowitz DJ (2013) Bipolar Disorder 3 Treatment of bipolar disorder. Lancet 381(9878):1672-1682

2. Freedman R (2003) Schizophrenia. New Engl J Med 349(18):1738-1749

3. Gilbert PL, Harris MJ, Mcadams LA, Jeste DV (1995) Neuroleptic withdrawal in schizophrenic-patients-a review of the literature. Arch Gen Psychiatry 52(3):173-188
4. Viguera AC, Nonacs R, Cohen LS, Tondo L, Murray A, Baldessarini RJ (2000) Risk of recurrence of bipolar disorder in pregnant and nonpregnant women after discontinuing lithium maintenance. Am J Psychiatry 157(2):179-184. https://doi. org/10.1176/appi.ajp.157.2.179

5. Viguera AC, Whitfield T, Baldessarini RJ, Newport DJ, Stowe Z, Reminick A, Zurick A, Cohen LS (2007) Risk of recurrence in women with bipolar disorder during pregnancy: prospective study of mood stabilizer discontinuation. Am J Psychiatry 164(12):1817-1824. https://doi.org/10.1176/appi.ajp.2007.06101 639

6. Reis M, Kallen B (2008) Maternal use of antipsychotics in early pregnancy and delivery outcome. J Clin Psychopharm 28(3):279-288. https://doi.org/10.1097/Jcp.0b013e318172b8d5

7. Kallen B, Tandberg A (1983) Lithium and pregnancy-a cohort study on manic-depressive women. Acta Psychiatry Scand 68(2):134-139. https://doi.org/10.1111/j.1600-0447.1983.tb069 91.x

8. Weinstein MR, Goldfield MD (1975) Cardiovascular malformations with lithium use during pregnancy. Am J Psychiatry 132(5):529-531

9. Diav-Citrin O, Shechtman S, Tahover E, Finkel-Pekarsky V, Arnon J, Kennedy D, Erebara A, Einarson A, Ornoy A (2014) Pregnancy outcome following in utero exposure to lithium: a prospective, comparative, Observational Study. Am J Psychiatry 171(7):785-794. https://doi.org/10.1176/appi.ajp.2014.12111402

10. Patorno E, Huybrechts KF, Bateman BT, Cohen JM, Desai RJ, Mogun H, Cohen LS, Hernandez-Diaz S (2017) Lithium Use in Pregnancy and the Risk of Cardiac Malformations. N Engl J Med 376(23):2245-2254. https://doi.org/10.1056/NEJMoa1612222

11. Galbally M, Snellen M, Power J (2014) Antipsychotic drugs in pregnancy: a review of their maternal and fetal effects. Ther Adv Drug Saf 5(2):100-109. https://doi.org/10.1177/2042098614 522682

12. Coughlin CG, Blackwell KA, Bartley C, Hay M, Yonkers KA, Bloch MH (2015) Obstetric and neonatal outcomes after antipsychotic medication exposure in pregnancy. Obstet Gynecol 125(5):1224-1235. https://doi.org/10.1097/AOG.0000000000 000759

13. Boden R, Lundgren M, Brandt L, Reutfors J, Andersen M, Kieler $H$ (2012) Risks of adverse pregnancy and birth outcomes in women treated or not treated with mood stabilisers for bipolar disorder: population based cohort study. BMJ 345:E7085. https ://doi.org/10.1136/bmj.e7085

14. Bennedsen BE, Mortensen PB, Olesen AV, Henriksen TB (1999) Preterm birth and intra-uterine growth retardation among children of women with schizophrenia. Br J Psychiatry 175:239-245. https://doi.org/10.1192/bjp.175.3.239

15. Jablensky AV, Morgan V, Zubrick SR, Bower C, Yellachich LA (2005) Pregnancy, delivery, and neonatal complications in a population cohort of women with schizophrenia and major affective disorders. Am J Psychiatry 162(1):79-91. https://doi. org/10.1176/appi.ajp.162.1.79

16. Barker DJP (1990) The Fetal and Infant Origins of Adult Disease. BMJ 301(6761):1111-1111

17. Schlotz W, Phillips DI (2009) Fetal origins of mental health: evidence and mechanisms. Brain Behav Immun 23(7):905-916. https://doi.org/10.1016/j.bbi.2009.02.001

18. Malhi GS, Outhred T (2016) Therapeutic mechanisms of lithium in bipolar disorder: recent advances and current understanding. CNS Drugs 30(10):931-949. https://doi.org/10.1007/s4026 3-016-0380-1

19. Chuang DM, Wang Z, Chiu CT (2011) GSK-3 as a target for lithium-induced neuroprotection against excitotoxicity in neuronal cultures and animal models of ischemic stroke. Front Mol Neurosci 4:15. https://doi.org/10.3389/fnmol.2011.00015 
20. Lally J, MacCabe JH (2015) Antipsychotic medication in schizophrenia: a review. Br Med Bull 114(1):169-179. https://doi. org/10.1093/bmb/ldv017 ldv017[pii]

21. Kusumi I, Boku S, Takahashi Y (2015) Psychopharmacology of atypical antipsychotic drugs: from the receptor binding profile to neuroprotection and neurogenesis. Psychiatry Clin Neurosci 69(5):243-258. https://doi.org/10.1111/pcn.12242

22. Hafeman DM, Chang KD, Garrett AS, Sanders EM, Phillips ML (2012) Effects of medication on neuroimaging findings in bipolar disorder: an updated review. Bipolar Disord 14(4):375-410. https ://doi.org/10.1111/j.1399-5618.2012.01023.x

23. Moncrieff J, Leo J (2010) A systematic review of the effects of antipsychotic drugs on brain volume. Psychol Med 40(9):14091422. https://doi.org/10.1017/s0033291709992297

24. Moher D, Liberati A, Tetzlaff J, Altman DG, Group P (2009) Preferred reporting items for systematic reviews and meta-analyses: the PRISMA statement. Open Med 3(3):e123-130

25. Hooijmans CR, Rovers MM, de Vries RB, Leenaars M, RitskesHoitinga M, Langendam MW (2014) SYRCLE's risk of bias tool for animal studies. BMC Med Res Methodol 14:43. https://doi. org/10.1186/1471-2288-14-43

26. Lo CK, Mertz D, Loeb M (2014) Newcastle-Ottawa Scale: comparing reviewers' to authors' assessments. BMC Med Res Methodol 14:45. https://doi.org/10.1186/1471-2288-14-45

27. StataCorp (2017) Stata: Release 15. StataCorp LP, College Station

28. Semple BD, Blomgren K, Gimlin K, Ferriero DM, NobleHaeusslein LJ (2013) Brain development in rodents and humans: identifying benchmarks of maturation and vulnerability to injury across species. Prog Neurobiol 106-107:1-16. https://doi.org/10.1016/j.pneurobio.2013.04.001

29. Sechzer JA, Lieberman KW, Alexander GJ (1986) Aberrant parenting and delayed offspring development in rats exposed to lithium. Biol Psychiatry 21(13):1258-1266. https://doi. org/10.1016/0006-3223(86)90308-2

30. Abu-Taweel GM (2012) Effects of perinatal exposure of lithium on neuro-behaviour of developing mice offspring. Indian J Exp Biol 50(10):696-701

31. Nery LR, Eltz NS, Martins L, Guerim LD, Pereira TC, Bogo MR, Vianna MRM (2014) Sustained behavioral effects of lithium exposure during early development in zebrafish: involvement of the Wnt-(beta)-catenin signaling pathway. Prog Neuro Psychopharmacol Biol Psychiatry 55:101-108. https://doi. org/10.1016/j.pnpbp.2014.04.011

32. Teixeira NA, Lopes RCM, Secoli SR (1995) Developmental toxicity of lithium treatment at prophylactic levels. Braz J Med Biol Res 28(2):230-239

33. Rider AA, Simonson M, Weng YS, Hsu JM (1978) Effect on rat pup growth and behavior of maternal lithium ingestion and low protein diet. Nutr Rep Int 17(6):595-605

34. Messiha FS (1986) Lithium and the neonate: developmental and metabolic aspects. Alcohol 3(2):107-112. https://doi. org/10.1016/0741-8329(86)90020-0

35. Brain PF, Ajarem JS, Petkov VV (1986) The application of ethopharmacological techniques to behavioural teratology: preliminary investigations. Acta Physiol Pharmacol Bulg 12(4):3-11

36. Schou M (1976) What happened later to lithium babiesfollow-up-study of children born without malformations. Acta Psychiatry Scand 54(3):193-197. https://doi. org/10.1111/j.1600-0447.1976.tb00112.x

37. Jacobson SJ, Jones K, Johnson K, Ceolin L, Kaur P, Sahn D, Donnenfeld AE, Rieder M, Santelli R, Smythe J, Pastuszak A, Einarson T, Koren G (1992) Prospective multicenter study of pregnancy outcome after lithium exposure during 1st trimester.
Lancet 339(8792):530-533. https://doi.org/10.1016/01406736(92)90346-5

38. van der Lugt NM, van de Maat JS, van Kamp IL, Knoppert-van der Klein EAM, Hovens JGFM, Walther FJ (2012) Fetal, neonatal and developmental outcomes of lithium-exposed pregnancies. Early Hum Dev 88(6):375-378. https://doi.org/10.1016/j.earlh umdev.2011.09.013

39. Kozma C (2005) Neonatal toxicity and transient neurodevelopmental deficits following prenatal exposure to lithium: another clinical report and a review of the literature. Am J Med Genet A 132A(4):441-444. https://doi.org/10.1002/ajmg.a.30501

40. Morrell P, Sutherland GR, Buamah PK, Oo M, Bain HH (1983) Lithium toxicity in a neonate. Arch Dis Child 58(7):539-541

41. Burt VK, Caryn B, Rosenstein WS, Altshuler LL (2010) Bipolar disorder and pregnancy: maintaining psychiatric stability in the real world of obstetric and psychiatric complications. Am J Psychiatry 167(8):892-897. https://doi.org/10.1176/appi. ajp.2009.09081248

42. Bogen DL, Sit D, Genovese A, Wisner KL (2012) Three cases of lithium exposure and exclusive breastfeeding. Arch Women Ment Health 15:69-72

43. Morrell P, Sutherland GR, Buamah PK (1983) Lithium toxicity in a neonate. Arch Dis Child 58(7):539-541

44. Frassetto F, Martel FT, Barjhoux CE, Villier C, Bot BL, Vincent F (2002) Goiter in a newborn exposed to lithium in utero. Ann Pharmacother 36(11):1745-1748

45. Bruses JL, Berninsone PM, Ojea SI, Azcurra JM (1991) The circling training rat model as a behavioral teratology test. Pharmacol Biochem Behav 38(4):739-745. https://doi.org/10.1016/00913057(91)90235-t

46. Wolansky MJ, Soiza-Reilly M, Fossati M, Azcurra JM (2004) Postnatal haloperidol eliminates the deficit in circling behavior produced by prenatal exposure to the same drug. Neurotoxicol Teratol 26(4):561-569. https://doi.org/10.1016/j.ntt.2004.04.006

47. Archer T, Fredriksson A (1992) Functional changes implicating dopaminergic systems following perinatal treatments. Dev Pharmacol Ther 18(3-4):201-222

48. Rosengarten H, Quartermain D (2002) Effect of prenatal administration of haloperidol, risperidone, quetiapine and olanzapine on spatial learning and retention in adult rats. Pharmacol Biochem Behav 72(3):575-579. https://doi.org/10.1016/S0091 $-3057(02) 00727 \mathrm{X}$

49. Singh Y, Jaiswal AK, Singh M, Bhattacharya SK (1997) Effect of prenatal haloperidol administration on anxiety patterns in rats. Indian J Exp Biol 35(12):1284-1290

50. Spear LP, Shalaby IA, Brick J (1980) Chronic administration of haloperidol during development: behavioral and psychopharmacological effects. Psychopharmacology 70(1):47-58. https://doi. org/10.1007/bf00432369

51. Singh KP, Singh M (2002) Effect of prenatal haloperidol exposure on behavioral alterations in rats. Neurotoxicol Teratol 24(4):497-502. https://doi.org/10.1016/s0892-0362(02)00189-7

52. Hull EM, Nishita JK, Bitran D, Dalterio S (1984) Perinatal dopamine-related drugs demasculinize rats. Science 224(4652):1011-1013

53. Stanford SC (2007) The open field test: reinventing the wheel. J Psychopharmacol 21(2):134-135. https://doi.org/10.1177/02698 81107073199

54. Singh Y, Jaiswal AK, Singh M, Bhattacharya SK (1998) Effect of prenatal diazepam, phenobarbital, haloperidol and fluoxetine exposure on foot shock induced aggression in rats. Indian J Exp Biol 36(10): 1023-1024

55. Scalzo FM, Ali SF, Holson RR (1989) Behavioral effects of prenatal haloperidol exposure. Pharmacol Biochem Behav 34(4):727-731. https://doi.org/10.1016/0091-3057(89)90266-9 
56. Williams R, Ali SF, Scalzo FM, Soliman K, Holson RR (1992) Prenatal haloperidol exposure-effects on brain weights and caudate neurotransmitter levels in rats. Brain Res Bull 29(3-4):449458. https://doi.org/10.1016/0361-9230(92)90082-9

57. Myslivecek J, Hassmannova J, Josifko M (1991) Impact of prenatal low-dose diazepam or chlorpromazine on reflex and motor development and inhibitory-learning. Homeost Health Dis 33(1-2):77-88

58. Hoffeld DR, McNew J, Webster RL (1968) Effect of tranquilizing drugs during pregnancy on activity of offspring. Nature 218(5139):357-358

59. Ordy JM, Samorajski T, Collins RL, Rolsten C (1966) Prenatal chlorpromazine effects on liver, survival and behavior of mice offspring. J Pharmacol Exp Ther 151(1):110-125

60. Robertson R, Majka J, Bokelman D (1979) Effects of prenatal exposure to chlorpromazine on postnatal development and behavior of rats. Toxicol Appl Pharmacol 48((1 II)):A117

61. Clark CV, Gorman D, Vernadakis A (1970) Effects of prenatal administration of psychotropic drugs on behavior of developing rats. Dev Psychobiol 3(4):225-235

62. Umemura T, Hironaka N, Takada K, Sasa H, Yanagita T (1983) Influence of chlorpromazine administered to rat dams in the peripartum and nursing periods on the learning behavior of the second generation. J Toxicol Sci 8(2):105-118

63. Jewett RE, Norton $S$ (1966) Effect of tranquilizing drugs on postnatal behavior. Exp Neurol 14(1):33-43

64. Szkilnik R, Brus R, Felinska W, Juraszczyk Z, Pyka U, Piechocka J, Kaminski M, Konecki J (1987) Effect of chlorpromazine administered to pregnant and lactating rat females on the behaviour of their offspring and its brain content of bioamines. Acta Med Pol 28(1-4):1-12

65. Rosengarten H, Friedhoff AJ (1979) Enduring changes in dopamine receptor cells of pups from drug administration to pregnant and nursing rats. Science 203(4385):1133-1135

66. Singh KP (2015) Prenatal exposure to a novel antipsychotic quetiapine: Impact onneuro-architecture, apoptotic neurodegeneration in fetalhippocampus and cognitive impairment in young rats. Int J Dev Neurosci 42:59-67

67. Singh KP, Singh MK, Singh M (2016) Effects of prenatal exposure to antipsychotic risperidone on developmental neurotoxicity, apoptotic neurodegeneration and neurobehavioral sequelae in rat offspring. Int J Dev Neurosci 52:13-23. https://doi.org/10.1016/j. ijdevneu.2016.05.006

68. Zuo J, Liu Z, Ouyang X, Liu H, Hao Y, Xu L, Lu XH (2008) Distinct neurobehavioral consequences of prenatal exposure to sulpiride (SUL) and risperidone (RIS) in rats. Prog NeuroPsychopharmacol Biol Psychiatry 32(2):387-397. https://doi. org/10.1016/j.pnpbp.2007.09.005

69. Auerbach JG, Hans SL, Marcus J, Maeir S (1992) Maternal psychotropic medication and neonatal behavior. Neurotoxicol Teratol 14(6):399-406. https://doi.org/10.1016/0892-0362(92)90050 $-\mathrm{k}$

70. Johnson KC, LaPrairie JL, Brennan PA, Stowe ZN, Newport DJ (2012) Prenatal antipsychotic exposure and neuromotor performance during infancy. Arch Gen Psychiatry 69(8):787-794. https ://doi.org/10.1001/archgenpsychiatry.2012.160

71. Mortensen JT, Olsen J, Larsen H, Bendsen J, Obel C, Sorensen HT (2003) Psychomotor development in children exposed in utero to benzodiazepines, antidepressants, neuroleptics, and anti-epileptics. Eur J Epidemiol 18(8):769-771. https://doi. org/10.1023/a:1025306304635

72. Peng M, Gao K, Ding Y, Ou J, Calabrese JR, Wu R, Zhao J (2013) Effects of prenatal exposure to atypical antipsychotics on postnatal development and growth of infants: a case-controlled, prospective study. Psychopharmacology 228(4):577-584. https ://doi.org/10.1007/s00213-013-3060-6
73. Platt JE, Friedhoff AJ, Broman SH, Bond R, Laska E, Lin SP (1989) Effects of prenatal neuroleptic drug exposure on motor performance in children. Hum Psychopharmacol 4(3):205-213

74. Hurault-Delarue C, Damase-Michel C, Finotto L, Guitard C, Vayssière C, Montastruc JL, Montastruc F, Lacroix I (2016) Psychomotor developmental effects of prenatal exposure to psychotropic drugs: a study in EFEMERIS database. Fundam Clin Pharmacol 30(5):476-482. https://doi.org/10.1111/fcp.12209

75. Petersen I, McCrea RL, Sammon CJ, Osborn DP, Evans SJ, Cowen PJ, Freemantle N, Nazareth I (2016) Risks and benefits of psychotropic medication in pregnancy: cohort studies based on UK electronic primary care health records review. Health Technol Assess 20(23):1-176

76. Stika L, Elisova K, Honzakova L, Hrochova H, Plechatova H, Strnadova J, Skop B, Svihovec J, Vachova M, Vinar O (1990) Effects of drug administration in pregnancy on children's school behaviour. Pharm Weekbl Sci 12(6):252-255

77. Slone D, Siskind V, Heinonen OP, Monson RR, Kaufman DW, Shapiro S (1977) Antenatal exposure to phenothiazines in relation to congenital-malformations, perinatal mortality-rate, birthweight, and intelligence quotient score. Am J Obstet Gynecol 128(5):486-488

78. Johnson KC, LaPrairie JL, Brennan PA, Stowe ZN, Newport DJ (2012) Prenatal antipsychotic exposure and neuromotor performance during infancy. Arch Gen Psychiatry 69(8):787-794. https ://doi.org/10.1001/archgenpsychiatry.2012.160

79. Peng M, Gao KM, Ding YL, Ou JJ, Calabrese JR, Wu RR, Zhao JP (2013) Effects of prenatal exposure to atypical antipsychotics on postnatal development and growth of infants: a case-controlled, prospective study. Psychopharmacology 228(4):577-584. https://doi.org/10.1007/s00213-013-3060-6

80. Shao P, Ou J, Peng M, Zhao J, Chen J, Wu R (2015) Effects of clozapine and other atypical antipsychotics on infants development who were exposed to as fetus: a post hoc analysis. PLoS One 10(4):e0123373. https://doi.org/10.1371/journ al.pone. 0123373

81. Cabuk D, Sayin A, Derinoz O, Biri A (2007) Quetiapine use for the treatment of manic episode during pregnancy. Arch Women's Ment Health 10(5):235-236. https://doi.org/10.1007/ s00737-007-0196-6

82. Hammond JE, Toseland PA (1970) Placental transfer of chlorpromazine. Case report. Arch Dis Child 45(239):139-140

83. Janjic V, Milovanovic DR, Ruzic Zecevic D, Loncar D, Laban O, Stepanovic M, Varjacic M, Obradovic S, Dejanovic SD, Jankovic S (2013) Zuclopenthixol decanoate in pregnancy: successful outcomes in two consecutive off springs of the same mother. Vojnosanit Pregl 70(5):526-529. https://doi. org/10.2298/vsp120208005j

84. Mendhekar DN, Andrade C (2011) Uneventful use of haloperidol and trihehexyphenidyl during three consecutive pregnancies. Arch Women Ment Health 14(1):83-84

85. O'Connor M, Johnson GH, James DI (1981) Intrauterine effects of phenothiazines. Med J Aust 1(8):416-417

86. Tanaka Y, Takada S, Kuwai T, Kawahara R, Doi K, Hazama H (1990) Psychotropics during pregnancy: serum haloperidol levels measured in 3 patients. Yonago Acta Med 33(1):71-78

87. Kenar A, Unal G (2015) Treatment of generalized anxiety diisorder in pregnancy and effects of psychotropic drugs in the infant: a case report. Eur Psychiatry 30:539

88. McCauley KM, Cross W, Kulkarni J (2014) Mental health: outcomes of 10 babies of mothers with a history of serious mental illness. J Psychiatry Ment Health Nurs 21(7):580-586. https://doi.org/10.1111/jpm.12111

89. Aichhorn W, Yazdi K, Kralovec K, Steiner H, Whitworth S, Stuppaeck C (2008) Olanzapine plasma concentration in 
a newborn. J Psychopharmacol 22(8):923-924. https://doi. org/10.1177/0269881107083849

90. Kim SW, Kim KM, Kim JM, Shin IS, Shin HY, Yang SJ, Yoon JS (2007) Use of long-acting injectable risperidone before and throughout pregnancy in schizophrenia. Prog Neuro Psychopharmacol Biol Psychiatry 31(2):543-545. https://doi. org/10.1016/j.pnpbp.2006.09.017

91. Mendhekar D, Lohia D (2008) Risperidone therapy in two successive pregnancies. J Neuropsychiatry Clin Neurosci 20(4):485-486

92. Mendhekar D, Sunder KR, Andrade C (2006) Aripiprazole use in a pregnant schizoaffective woman. Bipolar Disord 8(3):299300. https://doi.org/10.1111/j.1399-5618.2006.00316.x

93. Ratnayake T, Libretto SE (2002) No complications with risperidone treatment before and throughout pregnancy and during the nursing period. J Clin Psychiatry 63(1):76-77. https://doi. org/10.4088/JCP.v63n0114c

94. Rowe M, Gowda BA, Taylor D, Hannam S, Howard LM (2012) Neonatal hypoglycaemia following maternal olanzapine therapy during pregnancy: a case report. Ther Adv Psychopharmacol 2(6):265-268. https://doi.org/10.1177/2045125312460395

95. Stiegler A, Schaletzky R, Walter G, Wust R, Abele H, Goelz R, Farger G, Wiatr G, Fallgatter AJ, Batra A (2014) Olanzapine treatment during pregnancy and breastfeeding: a chance for women with psychotic illness? Psychopharmacology 231(15):3067-3069. https://doi.org/10.1007/s0021 3-014-3647-6

96. Tenyi T, Trixler M, Keresztes Z (2002) Quetiapine and pregnancy. Am J Psychiatry 159(4):674. https://doi.org/10.1176/ appi.ajp.159.4.674

97. Werremeyer A (2009) Ziprasidone and citalopram use in pregnancy and lactation in a woman with psychotic depression. Am J Psychiatry 166(11):1298. https://doi.org/10.1176/appi. ajp.2009.09060765

98. Rodríguez FJZ, Vega B, Hernández MRSW, Macías JAG, Leal FJV (2017) Use of paliperidone palmitate throughout a schizoaffective disorder patient's gestation period. Pharmacopsychiatry 50(1):38-40. https://doi.org/10.1055/s-0042-110492

99. Barnas C, Bergant A, Hummer M, Saria A, Fleischhacker W (1994) Clozapine concentrations in maternal and fetal plasma, amniotic fluid, and breast milk. Am J Psychiatry 151(6):945

100. Klier CM, Mossaheb N, Saria A, Schloegelhofer M, Zernig G (2007) Pharmacokinetics and elimination of quetiapine, venlafaxine, and trazodone during pregnancy and postpartum. J Clin Psychopharmacol 27(6):720-722. https://doi.org/10.1097/ JCP.0b013e31815a57d8

101. Gentile S (2015) Pharmacological management of borderline personality disorder in a pregnant woman with a previous history of alcohol addiction: a case report. Clin Drug Investig 35(11):761763. https://doi.org/10.1007/s40261-015-0337-z

102. Mendhekar DN (2007) Possible delayed speech acquisition with clozapine therapy during pregnancy and lactation [4]. J Neuropsychiatry Clin Neurosci 19(2):196-197. https://doi. org/10.1176/appi.neuropsych.19.2.196

103. Wichman CL (2009) Atypical antipsychotic use in pregnancy: a retrospective review. Arch Women's Ment Health 12(1):53-57. https://doi.org/10.1007/s00737-008-0044-3

104. Dabbert D, Heinze M (2006) Follow-up of a pregnancy with risperidone microspheres. Pharmacopsychiatry 39(6):235. https ://doi.org/10.1055/s-2006-951387

105. Karakula H, Szajer K, Spila B, Grzywa A, Chuchra M (2004) Clozapine and pregnancy: a case history. Pharmacopsychiatry 37(6):303-304. https://doi.org/10.1055/s-2004-832689

106. Stingl J, Berghöfer A, Bolk-Weischedel D (2000) Healthy outcome under olanzapine treatment in a pregnant woman. Pharmacopsychiatry $33: 78-80$
107. Schou M, Goldfield MD, Weinstein MR, Villeneuve A (1973) Lithium and pregnancy. I. report from the register of lithium babies. BMJ 2(5859):135-136

108. National collaborating centre for mental H (2014). doi: NBK305023 [bookaccession]

109. ACOG Committee on Practice Bulletins-Obstetrics (2008) ACOG Practice Bulletin: Clinical management guidelines for obstetrician-gynecologists number 92, April 2008 (replaces practice bulletin number 87, November 2007). Use of psychiatric medications during pregnancy and lactation. Obstet Gynecol 111(4):1001-1020. https://doi.org/10.1097/AOG.0b013e3181 $6 \mathrm{fd} 910$

110. Escudero I, Johnstone M (2014) Genetics of Schizophrenia. Curr Psychiatry Rep 16(11):502. https://doi.org/10.1007/s1192 0-014-0502-8

111. Seifuddin F, Pirooznia M, Judy JT, Goes FS, Potash JB, Zandi PP (2013) Systematic review of genome-wide gene expression studies of bipolar disorder. BMC Psychiatry 13:213. https://doi. org/10.1186/1471-244x-13-213

112. Scott $S$ (2012) Parenting quality and children's mental health: biological mechanisms and psychological interventions. Curr Opin Psychiatry 25(4):301-306. https://doi.org/10.1097/ Yco.0b013e328354a1c5

113. Leijdesdorff S, van Doesum K, Popma A, Klaassen R, van Amelsvoort T (2017) Prevalence of psychopathology in children of parents with mental illness and/or addiction: an up to date narrative review. Curr Opin Psychiatry 30(4):312-317. https:// doi.org/10.1097/YCO.0000000000000341

114. Maziade M, Rouleau N, Gingras N, Boutin P, Paradis ME, Jomphe V, Boutin J, Letourneau K, Gilbert E, Lefebvre AA, Dore MC, Marino C, Battaglia M, Merette C, Roy MA (2009) Shared neurocognitive dysfunctions in young offspring at extreme risk for schizophrenia or bipolar disorder in eastern quebec multigenerational families. Schizophr Bull 35(5):919-930. https://doi. org/10.1093/schbul/sbn058

115. Diwadkar VA, Goradia D, Hosanagar A, Mermon D, Montrose DM, Birmaher B, Axelson D, Rajarathinem R, Haddad L, Amirsadri A, Zajac-Benitez C, Rajan U, Keshavan MS (2011) Working memory and attention deficits in adolescent offspring of schizophrenia or bipolar patients: comparing vulnerability markers. Prog Neuropsychopharmacol Biol Psychiatry 35(5):13491354. https://doi.org/10.1016/j.pnpbp.2011.04.009

116. Jundong J, Kuja-Halkola R, Hultman C, Langstrom N, D’Onofrio BM, Lichtenstein P (2012) Poor school performance in offspring of patients with schizophrenia: what are the mechanisms? Psychol Med 42(1):111-123. https://doi.org/10.1017/S003329171 1001127

117. Burton BK, Thorup AAE, Jepsen JR, Poulsen G, Ellersgaard D, Spang KS, Christiani CJ, Hemager N, Gantriis D, Greve A, Mors O, Nordentoft M, Plessen KJ (2017) Impairments of motor function among children with a familial risk of schizophrenia or bipolar disorder at 7 years old in Denmark: an observational cohort study. Lancet Psychiatry 4(5):400-408. https://doi.org/10.1016/ s2215-0366(17)30103-7

118. Nery FG, Norris M, Eliassen JC, Weber WA, Blom TJ, Welge JA, Barzman DA, Strawn JR, Adler CM, Strakowski SM, DelBello MP (2017) White matter volumes in youth offspring of bipolar parents. J Affect Disord 209:246-253. https://doi.org/10.1016/j. jad.2016.11.023

119. Hanford LC, Hall GB, Minuzzi L, Sassi RB (2016) Gray matter volumes in symptomatic and asymptomatic offspring of parents diagnosed with bipolar disorder. Eur Child Adolesc Psychiatry 25(9):959-967. https://doi.org/10.1007/s00787-015-0809-y

120. de Leeuw M, Bohlken MM, Mandl RC, Hillegers MH, Kahn RS, Vink M (2017) Changes in White Matter Organization in Adolescent Offspring of Schizophrenia Patients. 
Neuropsychopharmacology 42(2):495-501. https://doi. org/10.1038/npp.2016.130

121. Sugranyes G, de la Serna E, Romero S, Sanchez-Gistau V, Calvo A, Moreno D, Baeza I, Diaz-Caneja CM, Sanchez-Gutierrez T, Janssen J, Bargallo N, Castro-Fornieles J (2015) Gray matter volume decrease distinguishes schizophrenia from bipolar offspring during childhood and adolescence. J Am Acad Child Adolesc Psychiatry. 54(8):677-684 e672. https://doi.org/10.1016/j. jaac.2015.05.003

122. Egger M, Smith GD (1998) Bias in location and selection of studies. BMJ 316(7124):61-66
123. Kapur S, Wadenberg ML, Remington G (2000) Are animal studies of antipsychotics appropriately dosed? Lessons from the bedside to the bench. Can J Psychiatry 45(3):241-246. https://doi. org/10.1177/070674370004500302

124. Institute of Medicine (2012) In: Ethical and scientific issues in studying the safety of approved drugs. National Academies Press, Washington. https://doi.org/10.17226/13219

125. Guess HA (2006) Exposure-time-varying hazard function ratios in case-control studies of drug effects. Pharmacoepidemiol Drug Saf 15(2):81-92. https://doi.org/10.1002/pds.1164 